\title{
الفقه السياسي
}

\section{عند الامام عحمد عبده}

\section{* إبراهيم عبد الباقي}

مقدمة:

قلةٌ من الفقهاء، في العصر الحديث، الذين خاضوا غمار السياسة، ولعلّ من أبرزهم الإمام الجليل محمد عبده -رحمه الله-، فإنه خاض في الشأن السياسي بقوة، وله آراء وأعمال عديدة فيها، منطلقا من فقهه للإسلام في كونه حضارة ومنهاج حياة، وفي وعيه بأهمية ولوج ميدان السياسة لتجاوز الأزمة الفكرية الحضارية الخانقة التي تعيشها الأمة العربية والإسلامية.

ولا تخرج شخصية الإمام محمد عبده، ككل الشخصيات العظيمة، عن نطاق بشريتها، إذ إنا معرضة للصواب والخطأ، وإن ندرت أخطاؤه، فلكل جواد كبوة، والحكم عليه ينبغي أن ينطلق من موافقة عمله للشرع، فإن وافقه كان مقبولاً، وإن خالفه كان مرفوضاً، أما إن كانت أعماله من قبيل الاجتهاد الذي لم يرد نص صريح بشأنه، فالحكم عليها إنما يكون بنتائجها وما تؤول إليه، أي أن الحكمم على أعماله إنما يكون وفق ضوابط الشرع أو مراعاة المصالح. إن دراسة شخصية الإمام في جانبها السياسي دراسة وافية أمر مُهمّ لفهم واقع العديد من حركات الإسلام السياسي؛ ذلك بأن الكثير من الحركات الإسلامية المعتدلة إنما انتهجت خط الإمام محمد عبده في أعمالها، فهو، وإن رحل، إلا أن الكثير من أفكاره باقية، يحملها تلامذته الفكريون. أولاً: الظروف الخحيطة بنشأة محمد عبده:

تحتّم دراسة شخصية الإمام محمد عبده، دراسة حالة العصر والظروف التي نشأ فيها، والتي أثرت على شخصيته، وهو كغيره من المصلحين الذين يتقدم ظهورهم عهد من الضعف في جميع مظاهر الحياة: الأدبية، والاجتماعية، والتعليمية، والقضائية، والدينية، والسياسية . 1 1

وسيتم قصر الكلام على الناحية النثرية من الأدب؛ ذلك بأن محمد عبده ناثر لا شاعر . ويمكن القول إن 
النثر في زمن نشأته قد أسفّ إسفافاً شديداً، فكان يتعثر في قيدين، هما: الخلو من المعاني والمواضيع المعتمدة على اتساع الثقافة، والإغراق في المحسنات البديعية والزخارف اللفظية الكثيرة التكلف، والتي يستعيض بها الكاتب عن فقره العقلي. ولم يكن للجرائد عناية بضبط المعاني، وتّذيب العبارات، وكان البارع من الكتّاب من يمهر في هذا الأسلوب، فيكتب طويلاً وكأنه ما كتب شيئا، ويقرأ القارئ له كثيراً وكأنه ما قرأ شيئاً . 2. الحالة الاجتماعية:

يمكن وصف حال المسلمين بالقول: إنه قد "وهت عُرى يقينهم بما غشيهم من الجهل بأصول دينهم، وقد تبع الضعف فساد في الأخلاق، وانتكاس في الطبائع، وانحطاط في الأنفس، حتى أصبح الجمهور الأعظم أشبه بالحيوانات الرّتّع (...) يأكلون، ويشربون، ويتناسلون، ويتنافسون في اللذات البهيمية." وقد أصاب الانحلال الخُلقي كلُُ فرد حتى هانت عليه نفسه وكرامته، كما دبّ الانقسام بين الناس، فلم يعد للفرد على الآخر حق ولا واجب، ولم تعد للجماعة على الأفراد عهود أو التزامات .

3. الحالة التعليمية:

وسيتم الاقتصار على أعلى مؤسسة تعليمية كانت آنذاك في مصر، وهي الأزهر الشريف، والتي من خلالها يمكن تكوين فكرة عامة عن التعليم في تلك الفترة: حيث لم يكن للهيئة التعليمية في الأزهر اهتمام بالعلوم الطبيعية والحديثة، مثل: علم التاريخ، والجغرافيا، والفلسفة، بل يرون ذلك بطالة وتضييعاً للزمن بلا فائدة، وينهون من يقرأكتب الفلسفة، ويشنون عليه الغارة، وربما ينسبُونَه للكفر. وكان من عادة الأزهريين أن يسخروا من المصريين المتعلمين في أوروبا، ويشبّهوهم بطير يمشي على الأرض تبختراً ووثباً، مع كونه لا يستطيع الطير في الجو، ولا السباحة في الماء، كما كانت طريقة التعليم في الأزهر أن يقرأ الطالب "الحواشي المطوّلة عديمة الجدوى، التي تدور حول مماحكات لفظية عقيمة، وجدل سفسطي تافه، وكان كل كتاب من هذه الكتب الأزهرية يقوم على إخراجه ثلاثة أو أربعة من المؤلفين، فيقرأ طالب العلم "المتن" لمؤلف، و "الشرح" لمؤلف ثان، و "الحاشية" لمؤلف ثالث، وقد يقرأ غير ذلك "تقريراً" لمؤلف رابع، وكل منها يفسر بعضه بعضا، وكل مؤلف يتعقب الآخر، ويذكر ما تحتمله عبارته من المعاني وما لا تحتمله، ثم يتعسف في إيراد اعتراضات قد تكون مستحيلة الوقوع. وكان الأزهريون يسمون الكتب الخالية من الشروح والحواشي والتقارير كتباً "غير مخدومة،" أما الكتب الحافلة بها فهي في نظرهم كتب "دسمة مباركة ". 
كانت الروح السائدة في الأزهر هي روح المحافظة على القديم، وتغليب النقل على العقل، والنفور من كل جديد. وقد بلغ من تعصب أنصار القديم لآرائهم أغم كانوا يرمون خصومهم بالضلال والزيغ عن الدين، فكانت "روح الجمود مسيطرة، حينذاك، على مناهج التعليم فصيّرته جافاً خالياً من كل ما ينفع الناس أو يُرغّب في العلم." وكان شيوخ الأزهر جامدين على "التراث القديم، الذي يتوارثون تلاوته دون تنبّه إلى وجوب تنقيته من الأساطير والأخطاء العلمية(...) وبما يجعله متناسباً مع روح العصر الحديث." وقد نحا التعليم الديني، بالذات، في ذلك الوقت، منحى "تقييد الفكر، والأخذ بما قال به الأقدمون، وعدم الخروج عما جاءت به الكتب القديمة من آراء وتعليقات. ومعنى هذا أنه كان يتجه إلى الحدّ من حرية الفكر في تفكيره، وإلزامه باتباع طريق أو طرق معينة، فالفرد، في ذاك الوقت، كان مستعبداً لتفكير من سبقه، مقيدا

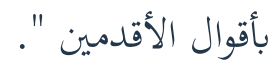

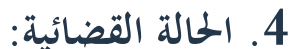

كان القضاء، آنذاك، قسمين: قضاء أهليّ (أو مديّّ)، وقضاء شرعيّ؛ ولذا انقسمت المحاكم القضائية إلى قسمين: محاكم أهلية، ومحاكم شرعية، فكان الحكم في المحاكم الأهلية على أصول القوانين الفرنسية الوضعية، في حين كانت البلاد تضج بالشكوى من فساد المحاكم الشرعية، ومن خلل إدارتا، وبطء أعمالها، حتى دعا البعض إلى إلغائها، وإضافة أعمالها إلى أعمال المحاكم الأهلية؛ بحجة توحيد القضاء، وبدعوى قدرة المحاكم الأهلية على الحكم في الأعمال الشخصية الدينية .

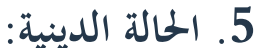

شهد جيل محمد عبده جموداً في العقائد والآراء أفسد نظام الحياة، وأعاق رجال الإصلاح عن نشر دعوقم، ووصل الحال أنْ "خلط الناس الدين بمجموعة من الشوائب التي خلّقتها له العصور المتوالية (...)، وذلك كالاعتقاد في الأولياء، ووقوع الكرامات لهم وخوارق العادات، وتبرّك المسلمين بزيارة قبورهم، والتشفع بأصحاب الأضرحة، وإقامة الموالد والنذور (...)، وكذلك انتشر مشايخ الطرق الذين يتغفلون العامة، وجعلوا الدين هزواً ولعباً، ووسيلة للارتزاق والكسب الرخيص، فاستبدلوا بذكر الله التغني والرقص (...)، ونسب الناس إليهم أعمالاً خارقة للعادة، وتوسلوا ببركاقم أحياء، والتمسوا عندهم الشفاعة، وأصبحت حلقاقم 
حرماً مقدساً، يلتمس فيها الأتباع والمريدون تحقيق ما لا يجوز تحققه عقلاً،" بل وصل الإسفاف لدرجة "أن أكثر الأئمة في هذا العهد من الجهال، حتى بأحكام الطهارة والصلاة، وأكثر الخطباء يغلطون على المنبر حتى بآيات القرآن، ويأتون في وعظهم بما يتبرأ الدين منه، من: الغش، والكذب على الله ورسوله ودينه، بسرد

$$
\text { الأحاديث الموضوعة والخرافات المصنوعة ". }
$$

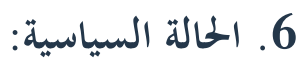

كانت البلاد تهوي بسرعة نحو الحضيض؛ نتيجة لفساد نظام الحكم، وتعاظم سلطة الأجانب، واندلاع الفتن من كل جانب، فامتدّ نفوذ الأجانب إلى إدارة الدولة وماليتها، فكان لا يتم إبرام أمر في الدولة دون استشارقم، وكان بجلس شورى القوانين صورة وحسْب، وانتشر في البلاد تيار من الرجعية والجمود، يعود بها إلى الفوضى والاضطراب، ومن دلائله: محاولة "عباس باشا الأول" الرجوع بالبلاد إلى العصور الوسطى: بالقضاء على المدارس، وبتعطيل المعامل والمصانع، وغير ذلك. كما كانت مصر أواخر عهد "الخديوي إسماعيل" مرهقة بديون ثقيلة، تقارب المائة مليون من الجنيهات، فتذرع الأجانب بحقهم في استيفاء هذه الديون مع فوائدها الباهظة، للتدخل في الشؤون الداخلية للبلاد، واكتساب الحقوق والامتيازات، وفرض سيطرتم غير المباشرة على أكثر مرافق الدولة. وقد عانى الفلاحون العبء الأكبر من هذه الكارثة، إذ فُرضت عليهم ضرائب فادحة لا طاقة لهم بأدائها، حتى عم البؤس الأرياف، وامتلأت أسواق المدن بالنساء اللواتي يأتين لبيع ملابسهن وقدورهن؛ لأن جباة الضرائب كانوا ينتظروهن في قراهن والسوط مُشْهر في أيديهم، مهذدّدين بجلد أزواجهن جلداً مُهيناً .

ثانياً: عوامل التكوين الفقهي لمحمد عبده: لقد أسهمت عوامل عدة في التكوين الفقهي لهذه الشخصية الفذة التي قامت بالعديد من الأعمال الجليلة، من ما:

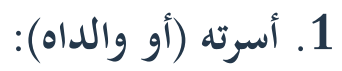

يمكن أن يكون هذا العامل أهمّ العوامل على الإطلاق، وقد دفعه إلى طلب العلم دفعاً؛ ذلك بأنّ والده أرجعه إلى الدراسة في المسجد الأحمديّ بعد أن هرب منه. ويعد البعض أن مواهب والدين محمد عبده 
الجسمية والنفسية قد انتقلت إليه، وأن علم النفس يؤيد فكرة انتقال المواهب والصفات من الآباء إلى الأبناء .

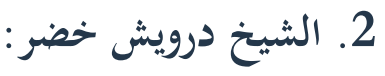

هو رجل صوفٌُّ، من أخوال أبي محمد عبده، قام بالاتصال بّ"الزاوية المسَّوسية"، وتعلم فيها وسيلة صفاء القلب، وعرف عن طريقها ما ينبغي اتباعُه في فهم الإسلام، وذلك بالاحتكام إلى القرآن والسنة الصحيحة، وعدم التعصب لما سواهما من أقوال أرباب المدارس والشرّاح والمؤلفين. وقد سبقت للشيخ درويش أسفار إلى صحراء ليبيا، حتى وصل إلى طرابلس الغرب، وجلس إلى السيد "حمد المنوني"، وأخذ عنه الطريقة الشاذلية،

وكان يحفظ الموطأ وبعض كتب الحديث، ويجيد حفظ القرآن وفهمه، ورجع بعد ذلك إلى قريته "كنيسة أورين"، واشتغل بما يشتغل به الناس من فلاحة الأرض، وكسب الرزق بالزراعة .

ويمكن إرجاع الفضل الأكبر إليه في توجيه محمد عبده إلى طريق العلم، حيث ذكر نفسه أنه لم يجد إماماً يرشده إلى ما وجه إليه نفسه إلا ذلك الشيخ، الذي أخرجه في بضعة أيام من سجن الجهل إلى فضاء المعرفة، ومن قيود التقليد إلى فضاء التوحيد، وهو الذي ردّ له ما كان غاب من غريزته، وكشف له ما كان خفي عنه مما أودع في فطرته. وقد التقى محمد عبده بالشيخ درويش عندما هرب إلى كنيسة أورين (من قرى مصر)، وفيها أخواله؛ لعدم رغبته الذهاب إلى طنطا للدراسة في الجامع الأمديّ، ويذكر محمد عبده عن نفسه أنه بقي في هذه القرية خمسة عشر يوما، تحولت فيها حالته، وبدل فيها رغبة غير رغبته، ولم يبق له إلا همّ واحد، وهو أن يكون كامل المعرفة، كامل أدب النفس. واستطاع الشيخ التأثير على محمد عبده للعودة إلى طنطا لإكمال دراسته، فذهب إلى الأزهر وداوم على طلب العلم متسلحاً بالعزلة والبعد عن الناس، حتى أنه كان يستغفر الله إذا كلّم شخصاً كلمة لغير ضرورة. وفي أواخر كل سنة دراسية كان يذهب إلى "علة نصر"، ويقيم بها شهرين: من منتصف شعبان إلى منتصف شوّال، فكان يجد الشيخ درويش قد سبقه هناك، فيبقى معه في مدارسة القرآن والعلم إلى يوم سفره. ولما مضى على ذلك سبع سنين، قال له الشيخ درويش، حين عودته إلى "حلة نصر" صيف سنة 1871: أما درست المنطق؟ أما درست الحساب؟ أما درست شيئاً من مبادئ الهندسة؟ فرد عليه حممد عبده: بعض هذه العلوم غير معروف الدراسة في الأزهر، فردّ الشيخ درويش: طالب العلم لا يعجز عن تحصيله في أي مكان، ثم دعاه إلى مخالطة الناس قائلاً: إلى متى هذه العزلة؟. وفي 
شوال من السنة نفسها، ودّعه الشيخ، وبكى بكاءً شديداً، ثم مات في السنة الموالية. لقد ربى الشيخ درويش محمد عبده على التعرض للإرشاد الديني، والتصدي لنصيحة المسلمين، فمهد بذلك السبيل التي سلكها به السيد جمال الدين الأفغاني، وهو سبيل الإصلاح العلمي والاجتماعي .

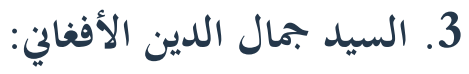

ينتمي السيد جمال الدين الأفغاني إلى بيت عظيم من بلاد الأفغان، ويتصل نسبه إلى المحدّث المشهور "علي الترمذي"، ثم يرتقي هذا النسب إلى سبط الرسول -عليه السلام- "الحسين بن علي بن أبي طالب"، رضي الله عنه. وقد ولد في قرية "أسعد آباد" سنة 1254هـ/1839م، وتلقى علوماً جمّةً، برع فيها جميعاً، مثل: العلوم العربية: (نحو، وصرف، ومعان، وبيان، وكتابة)، وعلوم الريعة: (تفسير، وحديث، وفقه، وأصول فقه،

وكلام، وتصوف)، والعلوم العقلية: (منطق، وحكمة عملية، وسياسية، ومنزلية، وقذذيبية، وحكمة نظرية غختصة بالطبيعة والهيئة)، وعلوم رياضية: (حساب، وهندسة، وجبر، وهيئة أفلاك)، إضافة إلى التاريخ العام والخاص، ونظريات الطب والتشريح، وغير ذلك. تُ سافر إلى الهند، وتعلم بعض العلوم الرياضية على الطريقة الأوروبية الحديثة، وجال كثيراً من البلدان، ووقف على عادات الكثير من الأمم، كما تقلّد مناصب عدّة في بلده، حتى أنه تقلد منصب "الوزير الأول"، وانتقل بعد ذلك إلى الهند بعد الانقلاب الذي أطاح حكومته، تم إلى السويس، فالأستانة، فإلى مصر مرة أخرى، وعند ذاك التقاه محمد عبده.

وقد اشتهر عن وفاته: أنه أصابه وجع في إحدى أسنانه، فأشار عليه الطبيب بخلعها، فحصل له التهاب موضعها، ظهر على إثرها سرطان في فكه، فأجريت له عمليات عدة لم تفلح، ولم يلبث أن توفي، وذلك سنة 1314هـ/1897م. لكن أشيع في كثير من البلدان أنه مات مسموماً، وقد صدرت الإرادة السلطانية إلى الجرائد العثمانية بأن لا تكتب في شأنه شيئاً، بل إن الحكومة في سوريا قامت بضبط جميع الجرائد والمجلات المصرية التي أبنته. وقد كتبت مجلة "الهلال" في تأبينه: "هو الذي كسر مقاطر التقليد الفكريّ والدينيّ واللغويّ، فكان إمام النهضة العلمية والقلمية والدينية في مصر وغيرها، كما كان إمام النهضة الاجتماعية والسياسية(..)، وأنه لو لم يكن من الأثر إلا الشيخ "حمد عبده"، لكفى السيد بالأستاذ،" فقد كان الأفغاني مشتهراً بلقب "السيد"، في حين أن محمد عبده كان مشتهراً بلقب "الأستاذ." أما بالنسبة لعلاقة محمد عبده بالأفغاني فقد نزل الأفغاني بمصر وعمره 32سنة، وصاحبه محمد عبده ابتداء 
من سنة 1287ه/1870م؛ ليشكلا معاً، بأعمالهم الفكرية وجهودهم العلمية، لواء القيادة لمسيرة النهضة والبعث والإحياء التي بدأتها شعوب الشرق في القرن التاسع عشر، وليمثلا لحظة فارقة وحقيقية وعملاقة في تققيق التجديد الذي ميّز الحياة العربية الحديثة والمعاصرة من الفترة التي عاشها العرب في ظل حكم المماليك والأتراك العثمانيين، كما سعى إلى دعوة أصدقائه لغشيان مجلسه، إذ وجد لديه روحاً جديدة غير مألوفة لدى شيوخ الأزهر، فاستنارت به الحركة الأزهرية، إذ نفث فيها من روح حماسته وفلسفته، كما قدّم خدمات جليلة لمصر، إذ نفخ فيها روح الحكومة النيابية، وألف فيها "الحزب الوطني الأول" بغرض تقييد سلطان الحكومة الشخصية، وغذّى تلاميذه ومريديه بعشق الحرية ووسائلها من: علم، وكتابة، وخطابة، وأرشد المسلمين إلى "الإصلاح الديني"، وكيفية الجمع بينه وبين "العلم العصري ".

ولعل من أهم الفوائد التي غنمها محمد عبده من الأفغاني: تلقيه عنه بعض العلوم الرياضية، والفلسفية، والكلامية، وانتشاله من الاتجاه الصوفي الذي كان عليه مدة من الزمن، وترغيبه في الإطلاع على ما في الكتب الحديثة المعرّبة، والتي وجد فيها لذة أخرى جديدة لم يكن يجدها فيما كان يقرأه من الكتب القديمة، واستطاع أن يجد عالماً جديداً أطال التحديق في آفاقه، ألا وهو عالم الفكر الغربي وما وصل إليه من علم حديث، وكان هذا هو الدور الثالث للإمام في طلب العلم: فأولها: طلب العلم على طريقة الأزهر، وثانيها: قراءة العلوم الإسلامية المكتوبة باللغة العربية، والثالث: النظر في علوم الإفرنج، كما مهّد الأفغاني محمد عبده طريق الصحافة منذ أن دربه على الكتابة والإنشاء في مختلف المجالات: الأدبية، والاجتماعية، والسياسية...إلخا، إضافة إلى تمرينه على الخطابة حتى برع فيها وفاق أستاذه . وقد اعترف محمد عبده بفضل أستاذه عليه، فقال: "إن والدي أعطاني حياة يشاركني فيها أخواي "علي" و"حروس"، والسيد جمال الدين الأفغاني أعطاني حياة أشارك بها محمد وإبراهيم وموسى وعيسى والأولياء والقديسين." كما بيّن محمد عبده "أن السيد جمال الدين الأفغاني هو موجد النهضة الاجتماعية بمصر من الجهتين: العلمية، والسياسية." ومن أوضح الأمور على تأثره بالأفغاني، أن مقالاته التي كان يكتبها في جريدة "الأهرام" ما هي إلا انعكاس لأفكار الأفغاني السياسية، ولعل هذا هو ما حمل "الخديوي توفيق" على أمره بالاعتزال في قريته، بعد أن قام بنفي الأفغاني، وعلى الرغم من ذلك لم يكصر محمد عبده نفسه في حدود ما تركه الأفغاني، بل امتحنه ونماه، وخلق منه نظاماً علمياً وعقلياً متعدد الجوانب، وإن كان موحّد المصدر 
والغاية

لقد لمح الأفغاني بفطنته ما يمتلكه الإمام من مميزات، فكان يقول له: "قل لي بالله أي أبناء الملوك أنت؟ مشيراً إلى ماكان عليه من الأخلاق العالية، وشرف النفس، وتحديه للحاكمين." وقال الأفغاني يوم رحيله عن مصر للمرة الأخيرة سنة 1296/1879/م: "لقد تركت لكم الشيخ محمد عبده، وكفى به لمصر عالماً." ثم انقطعت المراسلات بعد ذلك بينه وبين الأفغاني، وصارت الجفوة بينهما، بعد أن عنّفه الأفغاني أكثر من مرة على حذره وخوفه، واتممه بالجبن لموقفه من السياسة والإنجليز، وبلغ الأمر إلى حدّ توقف حممد عبده عن رثاء أستاذه في الصحف عند موته، واكتفى بالحزن عليه.

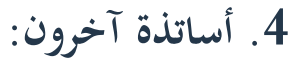

هناك أشخاص آخرون أسهموا بنوع ما في التكوين الفقهي لدى محمد عبده، منهم: "الشيخ حسن الطويل" الذي كان يدرّس المنطق وشيئاً من الفلسفة الإسلامية في الأزهر، لكن كان درسه احتمالات وحسنب، دون الجزم بأن المعنى كذا، وقد درس على يديه، وكان هو الذي صحبه في أول لقاء له مع الأفغاني، كذلك استفاد من "الشيخ محمد البسيولن" في أول تحصيله العلمي في دراسة الأدب العربي، واختاره دوناً عن أساتذة آخرين؛ ليكون مدرّسه في مرحلته الأخيرة من دراسته في الأزهر. ويمكن القول إن هذين الشيخين ينتميان إلى "الحزب الصوفي" في الأزهر، وهو الحزب الأقل في محافظته من "الحزب الشرعي المحافظ" الذي يتكون من الشرعيين .

ثالثاً: الآراء والفتاوى السياسية لغمدد عبده: حفلت حياة محمد عبده بالكثير من الأعمال الكبيرة التي يمكن استفادة العديد من الفوائد والعبر منها إن تم تدبرها، كما يمكن أن تنير طريق العمل الإسلامي والدعوة إلى الله، والسير بالمجتمع إلى طريق الخير، فقد تم تعيينه في منصب مفتي مصر، والذي يحتل موقعاً مهماً للغاية؛ بما يتمتع به المفتي من صلاحيات إصدار الفتاوى في كافة المجالات التي تسير عليها الدولة وتطبقها، كما أن سلطته تمتد خارج مصر إلى السودان، من حيث اختيار قضاة الشرع، لا سيما رئيسهم "قاضي القضاة"، فيقوم باختيار خيرة علماء الشرع علماً وخلقاً ومعرفة بأحوال الإدارة والعصر، كما أن للمفتي الحق في إبداء الرأي في إصلاح: الأوقاف، والأزهر، 
والمساجد. وأفكار محمد عبده واجتهاداته النظرية، والتي يرد بعضها في فتاواه، إنما تدفعه إلى صدارة التجديد في الإسلام، وتصب كلها في غر التجديد الحضاري للمسلم المعاصر، وقد استمر بالنهوض بمهمة الإفتاء مدة ست سنوات كاملة .

وتعدّ "الفتوى الترانسفالية" أشهر فتاواه، حيث أثثات ضجة واسعة في أوساط المسلمين، وكذلك في أوساط العلمانيين، وقد تأثثر فيها بمرحلة الدفاع عن الإسلام التي كان يمر بها الفكر الإسلامي. وهذه الفتوى عبارة عن ثلاثة أسئلة سأله إياها شخص من منطقة "الترانسفال" (في جنوب إفريقيا): فأباح في الأولى منها لبس البرنيطة الأجنبية، وفي الثانية أباح للمسلمين أكل الذبيحة التي تُضرب قبل الذبح بقصد إنهاكها وخلخلة قواها، وفي الثالثة أجاز صلاة الحنفيّ وراء الشافعيّ. كما أفتى بإباحة ادخار المسلمين لأموالهم، وأخذ الفوائد

$$
\text { والأرباح عليها لكن ضمن شروط معينة . }
$$

وهناك من يرى أن محمد عبده قد اتبع في أغلب فتاواه منطق العقل، كما أها امتازت بالميل إلى التسامح، واستقلال الرأي، والبعد عن التقليد، والموافقة ما بين روح الإسلام وبين مطالب الحياة العصرية .

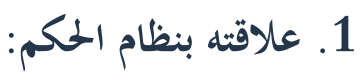

كان أول ما نُشر محمد عبده في جريدة "الأهرام" سنة 1293هـ/1876م، وكان لا يزال يلتزم السجع في أسلوبه، وعندما قام "أديب إسحاق" سنة 1877م، بوحي من أستاذه الأفغاني، بتأسيس جريدة أسبوعية اسمها "مصر"، وجّهت النقد للحكومة في أمور كثيرة، كما دافعت عن مجلس النواب؛ مما تسبّب في تعطيلها أكثر من مرة، اشترك كل من الأفغاني ومحمد عبده في تحريرها، ونشرا فيها مقالات سياسية عبّرت عن روح الأفغاني وكفاحه من أجل الحرية . تم قام "رياض باشا" بتعيين محمد عبده محرراً ثالثاً بجريدة "الوقائع" المصرية، لسان حال الحكومة الرسمي، وبعد ذلك رئيساً لقلم تحريرها(مرراً (أولا) سنة 1880م، وذلك حينما أمر "رياض باشا" قلم المطبوعات بأن يكتب مقالة عن مالية مصر، تلمّ بشيء من تاريخها الماضي ووضعيتها الحالية، وأن تنشر هذه المقالة في أول عدد يصدر من الجريدة الرسمية، وكان قد بقي يوم واحد على صدورها، فحاص كتّاب الجريدة وحاروا، ثم اهتدوا إلى محمد عبده، واحضروه من الأزهر، وكلّفوه بكتابتها، فكتبها في مجلسه، وتّم نشرها، فلما قرأها 
"رياض باشا" أُعجب بها إعجاباً شديداً، وسأل عن كاتبها، وزاد إعجابه أن وجد في الأزهر شاباً واقفاً على تاريخ المالية في مصر، عارفاً بجميع شؤوها، وقادراً على تبيان ذلك والإفصاح عنه، فاستدعاه، وسأله عن رأيه في إصلاح الجريدة، فعلم أنه المنفذ لما يرجوه من رقي لها، واختار محمد عبده معله بعض من تمرسوا الكتابة والتحرير من يثق بمم من تلاميذ الأفغاني، أولهم: "الشيخ عبد الكريم سلمان" الذي ظل إلى آخر حياته من أخلص أصدقائه، ونصيره في مجلس إدارة الأزهر، وكذلك "الشيخ سعد زغلول" الذي كان يومها مجاوراً أزهرياً في نغو الحادية والعشرين من العمر، و"الشيخ إبراهيم بك الهلباوي" الذي أصبح محامياً فيما بعد . وقد أحدث تعيين محمد عبده رئيساً للمجلة ما لم يكن على بال أحد، إذ أصبح هو المهيمن على الحكومة والأمة، ينتقد الأعمال والأقوال، وينتقل بالناس من حال إلى حال، حيث قام بوضع لائحة لقلم المطبوعات وللجريدة الرسمية، أجازها "رياض باشا"، كان من أحكامها: إلزام جميع إدارات الحكومة وبجالسها في العاصمة وغيرها بالكتابة إلى إدارة الجريدة مخبرة بأعمالها المنجزة، وما شرعت بتنفيذه فلم تتمه، كما ثُلزم المحاكم بإرسال نتائج أحكامها إليها، كذلك لإدارة الجريدة الحق في انتقاد كل الأعمال والمكاتبات الرسمية، ومراقبة كل الجرائد الوطنية والأجنبية التي تصدر في القطر المصري، بما يترتب على ذلك من تحر للحقيقة في كل ما يُكتب فيها، ومحاسبة من يثبت الذنب عليه من رجال الحكومة وغيرهم، ويذاع ذلك في الجريدة الرسمية، وكذلك مطالبة مديري الجرائد التي تنسب افتراءات إلى المسئولين وغيرهم بإثباتها، وإلا أُنذرت ثلاثاً، تم يمنع صدورها البتة، أو إلى أجلٍ تراه إدارة الجريدة الرسمية. كما أن من حق إدارة الجريدة الرسمية الفصل في كل نزاع بين جريدتين عربيتين بشكل لا يقبل المناقشة، ومن حق رئيس التحرير تخصيص قسم غير رسمي في

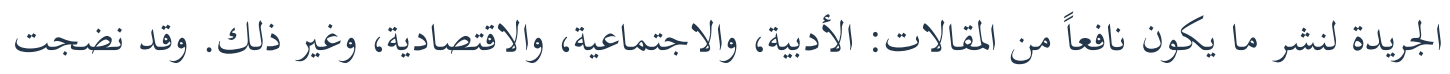
"الوقائع" في عهد محمد عبده، إذ رعاها بأفكاره الإصلاحية وانتقاداته السديدة، فتخطت واقعها اللغوي القديم، واعتمدت الكتابة السهلة المتينة، البعيدة عن الحشو والإطناب . ومن الفتاوى التي أبدى فيها محمد عبده آراءه في العلاقة بنظام الحكم، تلك التي أفتى فيها بوجوب استبدال الحاكم عند فساده بشروط فقال: "الخليفة عند المسلمين ليس بالمعصوم (...) ثم هو مطاع ما دام على المحجة وهج الكتاب والسنة، والمسلمون له بالمرصاد، فإذا انحرف عن النهج أقاموه عليه، أو إذا اعوجَّ قوَّموه بالنصيحة والإعذار إليه (..)، فإذا فارق الكتاب والسنة في عمله: وجب عليهم أن يستبدلوا به غيره، ما لم 
يكن في استبداله مفسدة تفوق المصلحة فيه، انطلاقاً من قاعدة: درء المفاسد مقدم على جلب المصالح (...) فالأمة أو نائب الأمة هو الذي ينصبه، والأمة هي صاحبة الحق في السيطرة عليه، وهي التي تخلعه متى رأت ذلك من مصلحتها، فهو حاكم مدني من جميع الوجوه."

كما أنه أفتى بعدم جواز تولية الإمامة للظالم، حيث قال: "الإمامة الصحيحة، والأسوة الحسنة، هي فيما تكون عليه الأرواح من الصفات الفاضلة والملكات العلمية التي تملك على صاحبها طرق العمل، فتسوقه إلى خيرها، وتردعه عن شرها، ولاحظّ للظالمين في شيء منها، وإنما هم لأصحاب الرسم، وأهل الخداع والانخداع بالظاهر؛ ولذلك يصف الفقهاء أعمالهم وأحكامهم بالرسمية (...)، وقد أخذوا من قوله تعالى(رَبّ اجْعَلْي مُقيَمَ الصَّلاةة وَمن ذُرِيَّت)) إبراهيم:40) حكماً أصولياً أن الظالم لا يجوز أن يُولّى منصب الإمامة العظمى، واشترطوا لصحة الخلافة فيما اشترطوا: العلم، والعدل." وذكر -أيضاً- ما يجب على الحاكم، فقال: "إن القتال في القرآن شُرع للدفاع عن الحق وأهله، وحماية الدعوة ونشرها، فعلى من يدّعي، من الملوك والأمراء أنه يحارب للدين، أن يهيي الدعوة الإسلامية، ويُعدّ لها عدهّا من العلم والحجة بحسب حال العصر وعلومه، ويقرن ذلك بالاستعداد التام لحمايتها من العدوان." فقد أوجب على الحكام إقامة شرائع الإممان في الرعية، حين خاطبهم بالقول: "أيها الأمراء والسلاطين (...) إن ما تستدلون به على أصل سلطتكم من القرآن، مقيد بكونكم من أهل الإيمان، وهذه آيات المؤمنين، وما أعلم الله به أهل الإيمان الصادقين، فعليكم بعد إقامة شُعب الإممان في أنفسكم، أن تقيموها في أنفس لـس رعيتكم، وتكونوا قدوة لعالمهم وعاملهم، وغنيهم وفقيرهم؛ لتكونوا أئمة هدى ونور، لا أئمة ضلالة وفجور، وإلا كان عليكم إثمكم وإثم جميع الأمم التي منيت بكم." فهو يرى أهمية تدخل السلطة الحاكمة لحفظ الملة، وذلك بقوله: "إن المتعنت الذي يبغي بجدله فتنة العوام، ليس له إلا الحديد، أي قوة السلطان، الذي يمنع

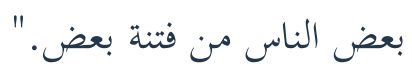
ويعتقد محمد عبده بضرورة التزام الحاكم بشروط معينة فيمن ينوب عنه، إذ يقول: "على ولي الأمر في مملكته أن لا يكل شيئاً من عمله إلا لأحد رجلين: -1 إما رجل يتصل به في جنسية سالمة من الضعف والتمزيق (...) يحملهم توقيرها واحترامها على التغالي في وقايتها من كل شين يدنو منها، ولم توهن روابطها اختلاف المشارب والأديان. 
-2 وإما رجل يجتمع معه في دين قامت جامعته مقام الجنسية، بل فاقت منزلته من القلوب منزلتها، كالدين الإسلامي الذي حلّ عند المسلمين -وإن اختلفت شعوبهم- محل كل رابطة نسبية. فإن كلا من الجامعتين

(الجنسية على النحو السابق، والدينية) مبدآن للحمية على الملك، والمنشآن للغيرة عليها." كما أنه يذكر الشروط المطلوبة في الحاكم، من خلال تفسيره لقوله تعالى حكاية عن "طالوت( "إنَّ اللّة

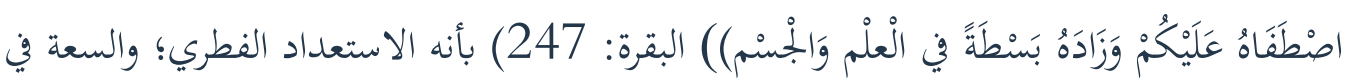
العلم(والمقصود بالعلم: العلم بحال الأمة ومواضع قوتما وضعفها، وجودة الفكر في تدبير شؤوها)، وبسطة الجسم (والتي يُقصد بها: صحته وكمال قواه، بما يستتبعه ذلك من الشجاعة، والقدرة على المدافعة، والهيبة، والوقار، وصحة الفكر على قاعدة: "العقل السليم في الجسم السليم.") ومع ذلك فمحمد عبده يرى وجوب مقاومة الظلم، إذ يقول: "ومن الظلم ترك مقاومة الظلم حتى يفشو، ويكون له السلطان الذي يذهب بكل سلطان." بل إنه أوجب على الأمة: "الأخذ على أيدي الظالمين، فإن الظلم أقبح المنكر(...)، والأمة هي التي تقوّم عوج الحكومة، والمعروف أن الحكومة الإسلامية مبنية على بلى

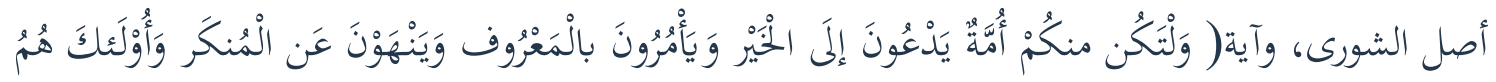
الُُْْْلحُونَ) ) آل عمران:104) أدل دليل عليه، والآية تفرض أن يكون في الناس جماعة متحدين أقوياء، يتولون الدعوة إلى الخير، والأمر بالمعروف والنهي عن المنكر . ويشرح رشيد رضا قول الإمام بالقول: وهذه الجماعة هي: بمعنى مجالس النواب في الحكومات الجمهورية والملكية المقيدة."

\section{2 الإصلاح في نظر محمد عبده:}

أحصى محمد رشيد رضا عدد المقالات الإصلاحية التي كتبها محمد عبده في جريدة "الوقائع" فبلغت 36 مقالاً، كلها يتحدث عن وجوب إصلاح مصر على أسس واعية منفتحة، على غرار سبل الإصلاح في أوروبا، كما تحتوي على نقد للمفاسد الاجتماعية والإدارية، ودعوة إلى بناء غضة رفيعة متدرجة، ومطالبة برفع مستوى التفكير الشعبي عبر ترقية مناهج التعليم ونشر وسائله، وإقامة حكم دستوري يقيّد سلطات الحكومة، ويؤمّن الحريات للشعب. وقد أشرف محمد عبده من خلال إدارته تحرير جريدة "الوقائع" (وهي الجريدة الرسمية)، على نظارات الحكومة وبجالسها ومصالحها، فأرشدهم إلى إصلاح أعمالهم، كما أشرف على رئى 
الأمة فقام بإصلاح أخلاقها، وإصلاح ما فسد من عاداتما بالوعظ الصحيح والإرشاد القويم، وأطل على الجرائد العربية، فعلّمها حسن التحرير، وربّاها على الصدق في القول، وجعل للصادق منها سلطاناً نصيراً و تأثيراً مأثوراً. فكان هذا مبدأ النهضة القلمية الحقيقية في مصر، وباعثاً لنهضة أدبية، وبحديداً في أساليب الكتابة . وقد أدت انتقادات محمد عبده للحكومة إلى تحرّيها الحق والعدل، واجتهادها في إصلاح كل نظارة ومديرية ومحافظة. وقد يصح القول بأنه كان للدولة حكومتان: إحداهما: مرشدة، وهي التي يقوم فيها محمد عبده برئاسة جريدة "الوقائع"، والأخرى: منفّذة، وهي الحكومة التي تتعاون مع الجريدة وتستجيب لمطالبها. وقد ابته محمد عبده إلى الكتابة؛ لماكان يراه من ابتحاه البلاد إلى شفير الهاوية، والذي أدى إليه فساد نظام الحكم، وتعاظم سلطة الأجانب، واندلاع الفتن من كل جانب. فخاض غمار السياسة بدافع من الحماسة التي أثارتا في نفسه آلام بلاده، وتأثره إلى حد كبير بصحبة الأفغاني ؛ وذلك كي يقف الناس على أسباب هذا التدهور، وليكشف لهم طرق العلاج التي لو أخذوا بها وتضافروا على تنفيذها بدقة وعناية وصبر واحتمال، كان فيها نجاة وخلاص لهم، كما راوده الأمل في إمكانية نشر أفكاره الاجتماعية بين أكبر عدد منكن من الناس. وقد برزت ملامح موقفه المستقل، الذي يمكن أن يحاسب على أساسه بعد تعيينه رئيساً لتحرير "الوقائع"، فتميزت شخصيته الفكرية ومواقفه العملية عن شخصية الأفغاني ومواقفه في عدد من المسائل، في مقدمتها موقفه من الوسيلة التي ينغي التخاذها، لتحقيق الغايات التي طرحها الأفغاني أمام شعوب الشرق يومئذ، وهي: التربية والتعليم، والإرشاد، والإصلاح · فرسالة محمد عبده لم تكن سياسية عحضة، بقدر ماكانت دينية واجتماعية وثقافية، تعمل على إحداث التأثير في الجمرى السياسي بصورة غير مباشرة. وهكذا كانت كتاباته سياسية بشكل غير مباشر؛ خوفا من إحراج بعض السياسيين الذي يجلّهم ويقدّر مواقفهم، وقناعة منه بأولوية الإصلاحات العامة على أي عمل آخر، فتمكّن من السمو بالعمل الصحفي، وأضفى عليه فيضاً من

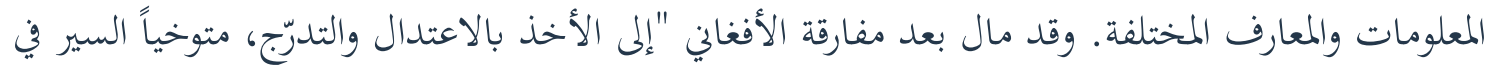
الإصلاح، لا من طريق السياسة والثورة، بل من طريق التعليم والتنوير، والتربية الدينية والاجتماعية"، كما أيقن بأن إصلاح المجتمع المصري هو في تقدم العلم والتربية والأخلاق، إذ هو التقدم الصحيح . 
كما كان قصد محمد عبده من كل كتاباته "إصلاح الدين"، الذي يدخل ضمنه الإصلاح السياسي، "فهذه الأفكار كلها التي يرد بعضها في فتاويه، والبعض الآخر في مقالاته، والبعض الثالث في رسائله وردوده على الذين يكتبون عليه، لا بحعل منه مفكراً اقتصادياً أو اجتماعياً أو سياسياً، ولكنها تدفعه إلى صدارة التجديد في الإسلام، بتجديد حياة المسلم، أو ما تواضعنا على تسميته بـ "الإصلاح الديني". وهو ليس إصلاحاً نظرياً بل متصلاً أوثق الاتصال بحياة المسلمين (...) فأضاف "الواقع" إلى "الفكر النظري". ولا يمكن قياس فكره "بمواقفه السياسية، أو فكره الاقتصادي والاجتماعي، بقدر ما يقاس بمجموع مواقفه من "الإصلاح الديني" الشامل لما سبق جميعه، فتلك هي القضية التي تأهل لها بحكم تكوينه ووعيه وتلمذته وخصومته للأفغاني، وبحكم ارتباطه العميق مع "الشارع الإسلامي" في مصر على وجه الخصوص." ويمكن إيجاز الدعوة الإصلاحية العامة لمحمد عبده في: "تنقية الإسلام" من شوائب عصور الانططاط، والعودة إلى التراث دون وسائط أو نقل أو تقليد، و"إعادة النظر" في كل ما يتصل بالمذاهب الإسلامية في ضوء العلم المعاصر. وإن قول البعض بأن الإمام اهتم بالإصلاح الديني دون العمل على التنوير السياسي العام، أو أن الإمام قد فرّق في إصلاحاته بين "الإصلاح الديني" و "الإصلاح السياسي"، إذ جعل كُلاً منهما قسماً مستقلاً بذاته، يُردّ عليه بأن الإصلاح الديني لدى الإمام شامل للإصلاح السياسي، وإذا لم يكن الإمام مكثراً من الكلام عن الإصلاح السياسي، فإن ذلك لفقهه ضرورات الواقع وأولويات المرحلة التي يعيشها. فبعد الانتكاسات التي مرَّ بها في أعماله السياسية مع الأفغاني اختار "طريقاً آخر، رسمه لنفسه، يؤدي في نظره إلى الغاية ذاما التي كان يريد "الأفغاني" الوصول إليها من طريق السياسة، وهي: هضة المسلمين، وصيانتهم لحقهم في أن يعيشوا متساوين مع غيرهم في الحياة، حريصين على أن لا يُستذلوا لأحد أجنبي عنهم، مع استعانته في الوصول إلى هذه الغاية، بالمبادئ ذاتحا التي عُنى بها "جمال الدين،" فكانت طريقه التي سلكها هي "التربية": تربية الشعب، وتربية القادة والموجهّين." 3. - 2 نظرته لتجديد الفكر الديني:

امتازت كتابات محمد عبده من غيره في وقته: بقدرته على المزج بين العقيدة الإسلامية، وبين التراث الليبرالي الإنساني والفكري التطوري بشكل خاص، والذي أدى إلى نشوء مروحة من الأفكار الجديدة والسلفية في الفكر العربي، فظهر له أتباع ينادون بضرورة التوفيق بين الفكر العربي-الإسلامي والفكر الحديث. وإذاكان 
مصطلح "السلفية" يفترض انكفاءً ما، فإن محمد عبده ليس سلفياً بهذا المعنى، وإنما هو عصري ينتمي إلى التراث الإسلامي؛ إذ إنه يوضح في كتاباته أن مأثور الدين هو المرجع في بحديد الدين، وأن بحديد الحياة الدنيا يستلزم الاستعانة بكل التجارب والأفكار والعلوم والنظريات التي أبدعها الإنسان، سواء في عصور ما قبل الإسلام، أو ما بعده، وسواء أكان المبدع لهذه العلوم من المسلمين أم من غيرهم. وكانت إحدى الغايات الرئيسة لمحمد عبده في كتاباته "أن يُظهر إمكان التوفيق بين الإسلام وبين الفكر الحديث، وأن يبين كيفية تحقيق ذلك." فأقام فكره على محاولة الجمع بين القديم والجديد، بأن يكون القديم أصلا يُطعّم، إلى درجة محدودة، بعناصر الجديد. وقد أثّرت بحربته في هذا المجال على الفكر الإسلامي؛ ذلك بأنه عمل على محاربة الجمود الديني، وفساد علماء الدين، من خلال الانفتاح على العلم ومفاهيم التمدّن، واللجوء إلى العقل لا التقليد، كما أنه أسهم في نشر بعض الآراء والمواقف الحميثة، التي اضطر إلى الاستعانة بها في مواجهة المفكرين المسيحيين والغربيين، على الرغم من وعيه بمخاطر انتشار الأفكار والقيم الغربية في المجتمع الإسلامي. وكان موقفه هذا إيذاناً ببدء تسرب هذه القيم إلى الفكر الإسلامي، على عكس ما كان يريد ويتمنى، حتى عدّه البعض أنه أحد الذين أسهموا بإدخال "العلمانية" إلى العالم العربي والإسلامي، إذ "فتح الباب على مصراعيه لكل أولئك الذين أتوا بعده من المستغربين، أمثال: قاسم أمين، وعلي عبد الرازق، وغيرهم الذين طبّقوا مدافعاته ذات النزعة التحررية على استنتاجاتم المنطقية." فقد ظهر من تلامذته المتابعين لخطه التوفيقي: في الميدان الاجتماعي: قاسم أمين الذي عُني بقضايا المرأة وتحريرها، وفي الميدان السياسي، برز سعد زغلول الذي كان هدفه إصلاح النظم السياسية دون المساس بالدعائم التي تقوم عليها العقيدة، ويف الناحية الدينية: خلّف محمد عبده الكثير من تلامذته الذين استطاعوا تولي مقاليد الأمور في الأزهر ومواصلة المهمة التي بدأها، وفي ميدان الفلسفة: برز من تلامذته مصطفى عبد الرازق الذي ألف كتاب "الإسلام وأصول الحكم" الذي أثار ضجة كبيزة وحوكم بسببه .

وفقاً لتعريف "رونوفن "Renouvin و و"جان باتيست دوروزل "B.Duroselle عن المناضل والإصلاحي، بأن المناضل هو الذي يستهويه القتال من أجل فكرة يؤمن بها، أما الإصلاحي فهو الذي يُقضّل الثفاهم على الاقتنال، يكون الأفغاني هو المناضل أو الثوري، ويكون محمد عبده هو المصلح، وهذا لا ينقص من قدره، إذ كل مخلوق ميسّر لما خُحلق له؛ ذلك بأن فكره قد امتاز بـ"الوسطية" بين أولئك الذي يرون 
أن كل ما فعله القدماء أو فكروا فيه هو الصحيح الذي يجب أن يُتبّع، وبذلك يفقدون الثقة في كل ما لم تأت به الأوائل، أو لم يجدوه في تقاليد الوسط الذي نشأوا فيه وبين أولئك الذين طغت عليهم رغبتهم في الجلدة والابتكار، فأصبحوا يؤمنون بأن كل ما نقل من الماضي يجب أن ينقرض، وأن المثل الأعلى في الحياة هو فيما يُستجد من مناهج العيش ومباهج الاستمتاع. فلم يخزج محمد عبده في كل أعماله، ومنها كتاباته، وفي كل أطوار حياته، عن حدود "الاعتدال" و "الإصلاح"، لا تحت الضغط، ولا الإرهاب، ولا السجن، ولا النفي؛ لأن تكوينه الفكري الخاص يميل نخو "الوسط"، في الوسائل والغايات . لقد حمل محمد عبده القبس بعد الأفغاني، وصرف أكثر جهوده إلى الدين دون السياسة، وتوخى في التثقيف التؤدة والأناة دون الطفرة والعنف. فهو بعد مفارقة الأفغاني، الذي كان له تأثير كبير عليه، رجع إلى ميله الأصلي في الاهتمام بالتربية، ونقص اهتمامه بالسياسة، لكن لم يلغ تماما. وكان متدرجا في منهجه التربوي، والذي استمده من القرآن الكريم، وعمل السلف الصالح، كعمر بن عبد العزيز الذي قال لابنه عندما رأى أباه تباطأ في إصلاحاته زمن خلافته: "مالك لا تنفذ الأمور؟ فو الله ما أبالي لو أن القدور غلت بي وبك في الحق. قال له عمر: لا تعجل يا بني، فإن الله ذم الخمر في القرآن مرتين، وحرّمها في الثالثة، وإني أخاف أن أحمل الناس على الحق جملة، فيدفعونه جملة، ويكون من ذا فتنة." فلا يصح أن يوصف هذا السلوك من الإمام بالجبن، الذي وصفه به البعض في علاقته مع الإنجليز - كما سيرد-، بل هو فقه الكتاب والسنة وأعمال السلف الصالح الذي استمد منه منهجه. وقد ظهر إيمانه بالتدرج من خلال قوله في كتاباته: "إنه لا يُرجى إصلاح لشعب جاهل إلا إذا تعلم وأخذ قسطه من الثقافة، وأُعدّ إعداداً صحيحاً يطهره مما غرق فيه من خرافات وأساطير، ويثقفه حتى يشعر بحاجته إلى الإصلاح، ويطلب لنفسه الكمال من طريق الكمال، ويطلبه لنفسه برغبة صادقة وميل شغوف"، ومما جاء في محاوراته مع "عرابي": "إن أول ما يجب أن يُبدأ به: التربية والتعليم(...) وليس من الحكمة أن تُعطى الرعية ما لم تستعد له، فذلك بمثابة تمكين القاصر من التصرف بماله قبل بلوغه سن الرشد."

وفي طريقة لتجديد الفكر الديني، عمل محمد عبده على التصدي لذلك التحدي الذي تمثل في فكرية العصور الوسطى، فكرية العصر "المملوكي العثماني" التي قَدّست ما لا يستحق التقديس من الحواشي والمتون، ولم تكن دعوته هذه محلية خاصة بمصر، ومما يؤكد ذلك "أن إقامة الشيخ محمد عبده في بيروت، كان لها 
آثارها الكبيرة في مجال اليقظة العربية (...)، وأنه عندما سافر إلى الجزائر تأثر به علماؤها، ومنهم الإمام عبد الحميد بن باديس المصلح الجزائري الكبير، وقد بلغ من حبه للإمام أن سمى ابنه "عبده"؛ تخليداً لذكرى محمد عبده". وقد جسّد محمد عبده في كتاباته، بوصفه مصلحاً ومفكراً، الفكر الإسلامي الحديث في مرحلته الأولى، "وهي مرحلة الدفاع عن الذات الإسلامية، الذي غلب عليها الاتحاه الإصلاحي التدرجي(..)، وابتحه الصراع المباشر مع العدو إلى: إصلاح التعليم والمدارس، وإصلاح المناهج، والمعاهد الدينية، والمحاكم الشرعية، ولو بتنسيق معهم. وهذا هو موقف الدفاع الطبيعي المطلوب يومئذ، الذي استند على عقلانية حديثة، أخضعت كثيراً من المشكلات التي أثيرت حول الإسلام؛ من أجل إثبات معقولية عقائد الإسلام وشرائعه، في حدود أقصى ما يمكن من ضوابط التأويل في الإسلام (...)، ولا شك أن ذلك الموقف الدفاعي قد أدى دوره التاريخي، فأنقذ الإسلام وتاريخه وحضارته من السقوط النهائي الذي كانت تلك الدوائر الاستعمارية المهاجمة تزعمه وتتوقعه(...) ونجد ذلك الموقف الدفاعي المخلص الواعي بمساحته كلها في كتب الإمام "محمد عبده"، وفي منهجه في التفسير، وفي معظم ما كتبه من مقالات وفتاوى فيما بعد(...)، وإن ذلك الموقف هو الممكن، يومئذ، أمام قوة تقدم مؤسسات الحضارة الغربية، واهيار المجتمع الإسلامي في مجالات الحياة كافة (...)، فلكل مرحلة خطتها، ولكل تحدّ في الحياة استجابته الطبيعية." إن انتهاج محمد عبده لطريق التأليف والكتابة بشكل أساسي، نابع من فكره العملي؛ نظراً لأن هذا التأليف، وتلك الكتابة، هو حوار مباشر مع أحداث الحياة من حوله، وليس "يوتوبيا" (خيال). وكان السؤال المطروح في كثير من كتاباته، وفي غالب تفكيره: كيف السبيل إلى دمج التراث العربي القديم في حياة العرب المعاصرة، لتكون لهم حياة عربية ومعاصرة في آن معاًٌ وكانت إجابته تتمثل في: البحث عن طرائق السلوك التي يمكن نقلها عن الأسلاف العرب، بما لا يتعارض وطرائق السلوك التي استلزمها العلم المعاصر والمشكلات المعاصرة. وقد حاول جاهداً فيما كتبه أن يوضّح الحلقة التي توفق بين مقتضيات العلم وبين مقومات الإنسان، بما يزيل الصراع بينهما . لقد أراد محمد عبده أن يرد إلى لإسلام اعتباره؛ كي يستعيد حيويته وقوته وعنفوانه، وليتمكن المجتمع المسلم من الازدهار مجدداً، وكانت منهجيته هي: التنقيب في بطون التاريخ الإسلامي؛ بغية التعرف على حقيقة الضعف الذي انتاب المجتمع المسلم، والتماساً لأسباب العلاج، فوجد أن العلة هي في: انخراف المسلمين عن 
دينهم الإسلامي الحقيقي في بساطته الأولى أيام الخلفاء الراشدين، وأن العلاج يكون بالتمسك بكتاب الله وتعاليم دينه، بعد أن يتم تطهيرها من كل ما علق بها من شوائب وبدع وخرافات، كما أن العلة تكمن أيضاً- في استبداد حكام المسلمين الظلمة، وبشكل أوضح، فالتخلف، في رأيه، إنما يعود إلى سببين: أحدهما: داخلي، والآخر: خارجي، والسبب الخارجي: يتمثل في طغيان الثقافة الغربية على حياة العرب والمسلمين، دون هضم لها ولا تحليل، إضافة إلى فرض نوع من القيم والنظم غير النابعة من نظام فكر الأمة، ولا من معطيات واقعها، أما السبب الداخليّ فيتمثل في تخلف بعض الذين نصّبوا أنفسهم قادة وأوصياء على الفكر الإسلامي، وحيلولتهم دون الاجتهاد في تأويله حسبما يستجد من أمور . وعلى كلّ، فقد انطلق فكر محمد عبده، كما انطلق فكر أستاذه الأفغاني من قبل، إلى الاهتمام أكثر بقضية

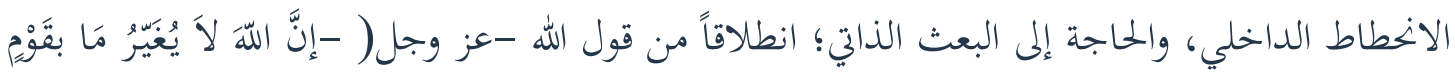
حَتَّى يُغْيَرُوْاً مَا بَأَنْفُسهمْ) ) الرعد: 11)، وأن الحل يكون بالدعوة إلى "تحرير الفكر من قيد التقليد، وفهم الدين على طريقة سلف الأمة." لذلك أصبح محمد عبده في نظر الكثيرين: أحد رواد الفكر التحرري الحديث، ومن المنددين بالجمود الفكري، والمنادين بالحرية الفكرية، وبحرية الرأي والتعبير، وبحرية الشعوب. فقد أسهم في دفع العقل ليحكم في مسائل لم يجرؤ غيره من العلماء على إعطاء آراء بشأها، وإنما اكتفوا بحكاية وشرح آراء من سبقهم، مثل مسألة الجبر والاختيار، فهو لمم يقنع بدور التبليغ فقط، بل انتهى إلى حلول وآراء بتعل قارئها يعتقد بأن صاحبها قد أصاب كبد الحقيقة، وقد أدت خصوبة فكره ودسامة إنتاجه إلى تعرضه لانتقاد الكثيرين، وهذا أمر عادي لكل تفكير يماول التعرض للعويص من المشاكل، وإيجاد رأي

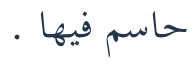

يردّ محمد عبده في كتاباته، في سياق الخطاب الدفاعي الذي نشأ في الفكر الإسلامي الحديث، على أصحاب الفكر الغربي (سواء أكانوا أوروبيين أم عرباً) أفكارهم السلبية بتحاه الفكر الإسلامي والمسلمين، من مثل "هانوتو"، و"دينان"، و "فرح أنطوان". ويصدق على كتابات الإمام وصف البعض بأنه يتجه "بوضوح

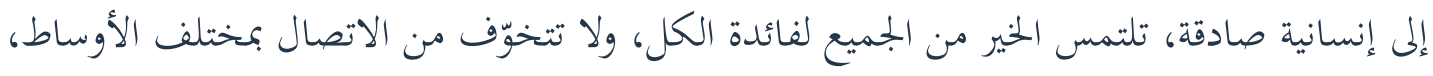
وشتى البيئات، والبحث معها عمَّا يساعد على التقدم، والعمران، وتحسين حالة المجتمع البشري، والارتفاع به للمستوى العالي الذي خلق من أجله، فإن كل جها مبذول في هذا الصدد من أجل بلادنا ووسطنا، يعلُّ في 
الفكر الإسلامي، جزءاً من المجهود العام الذي تبذله الإنسانية جمعاء لتحقيق عالم أفضل." وكانت نظرة محمد عبده العامة للإسلام هي دافعه للرد على المستشرقين وغيرهم ممن لم يفهموا الإسلام على

وجهه الصحيح، أو الذين فهموه لكنهم معاندون؛ كي يعذر إلى الله فيهم ولا يكون لهم حجة، ولكي لا ينخدع بمم الغر السذج من المسلمين. فهو "لم يكن يتوجه بكتاباته إلى المسلمين المؤمنين المتسائلين إذا كان بالإمكان قبول المدنية الحديثة، بقدر ما توجه بها إلى الآخذين بالثقافة الحديثة، الشّاكين في صلاح الإسلام." وقد عوّّل بشكل قوي على المثقفين لا العامة، لكنه -مع ذلك- لمُ ينس في كتاباته عموم المسلمين، بل دعا لتوحيدهم، فقد كانت "الوحدة الإسلامية واحدة من أهم أمانيه وأهدافه المثالية. فكان

يقوم بجهود شديدة للتوحيد بين الشيعة والسنة، وقام بعمل لقاءات عدة معهم هو وأستاذه الأفغاني." واكتفى محمد عبده في دفاعه عن قضية الحرية ومطالبته بها بالنهج الإسلامي وحده، فكان "يدافع عن قضية الحرية بكلمات إسلامية، دون أن يستند إلى الثورة الفرنسية" أو إلى مبادئها، إذ كان يرى في مبادئ الإسلام ما يكفي وزيادة. ولم يكن قصده من المطالبة بالأخذ بالأنظمة الحديثة هو نقلها دون مراعاة خصوصية العالم الإسلامي، إذ إنه يرفض "زرع مؤسسات وقوانين أوروبية في مصر؛ لأنه أمر لا يمكن تطبيقه، رغم إعجابه

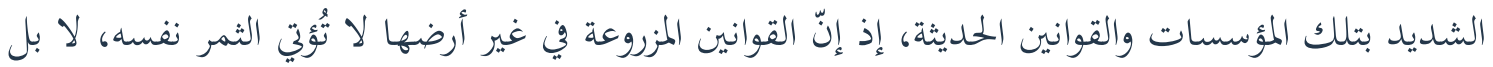

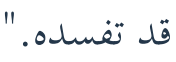

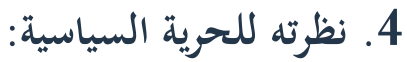

تلخصت دعوة محمد عبده في غالب كتاباته على أمرين أولهما: التحرر الفكري من الجمود والتقليد والرجعية الدينية، بسلوك طريق العقل لتجديد الدين، وإحياء الدراسات الفلسفية الممزوجة بالإلهيات، وإحداث ثورة فكرية "تغربل" بها موروثاتنا الدينية عن الأولين، وخصوصاً أهل قرون التخلف والركاكة والانخطاط. وثانيهما: التحرر السياسي من نفوذ الاستعمار الغربي الزاحف على المنطقة، والتصدي له "بالنهضة الحضارية" لمغالبته، وبتسيد الفكر الإسلامي الشوريّ في مؤسسات دستورية ونيابية حديثة، وتقييد سلطات الحكومات بالدساتير والقوانين، وإطلاق طاقات الجمهور الواسعة في الخلق والإبداع والبناء. وكل ذلك بوساطة "الثورة" على المعوقات التي تعترض الجماهير في هذا الطريق." وإذا كان البعض قد رأى أنه كان "انتقائياً في أخذه بالتراث" فإن آخرين يرون أن هذا الأخذ مع مزجه بشيء من النزعة التوفيقية بين الفكرين الإسلامي والغربي، 
هو أمر ايجابيُّ، أهَّله ليكون ضمن جماعة المفكرين المجددين في التاريخ الإسلامي الحديث. فلم تكن كتاباته

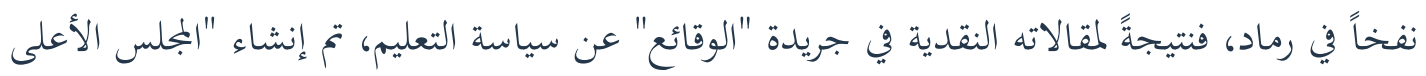
للمعارف،" وانتخب عضواً فيه. فكان يفقه واقعه المحيط، ويعمل على أساسه، فتأتي جهوده مثمرة في غالب الأحيان.

لقد أسس محمد عبده، مذهبه في "الحرية السياسية" على نظرة ما ورائية، تتوسط بين الجبر والاختيار، وتأخذ بالقضاء والقدر تعبيراً عن العلم والإرادة الإلهيين، فنظرته للحرية السياسية تنبثق، بالدرجة الأولى، من مبدأ الشورى في الإسلام (وهذا واضح في اعتماده مصطلح الشورى دون الديمقراطية). ويتمثل جانب الجبر في مذهب الحرية السياسية لديه بإرجاعه أسباب الانخطاط السياسي للمسلمين إلى الدورة التاريخية الطبيعية، متأثرا في ذلك بابن خلدون، أي أن هذا الانططاط قدر محتوم على الأمة، وسنة كونية لا مفر منها، لكن هذه النظرة تعطي للمتخاذلين من المسلمين نوعاً من التسويغ لتكاسلهم عن العمل، من أجل تحقيق التقدم الحضاري للأمة، بل يمنح الحكام الفاسدين من المسلمين الذي مالوا إلى إيقاع المسلمين فيما هم عليه من الضعف والكسل والجهل لإحكام السيطرة عليهم، مسوّغاً لتخاذلهم عن العمل لرفعة الأمة والنهوض الحضاري بها، وهذا هو جانب الاختيار في نظرته للحرية السياسية؛ ذلك بأن هؤلاء الحكام هم الذين اختاروا طريق "الانطاط الحضاري"، وهم الذين يمكنهم سلوك طريق آخر غيره يقود الأمة لما فيه صلاحها، وهو بذلك إنما يُسقط الشعوب الإسلامية من حسابه، مُعوّلاً على الحكام فقط . وهو يرى، طبقاً لمنهجه المتدرج، أنه لابدّ من الإصلاح الخنقي أولاً، ثم الإصلاح السياسي ثانياً، على اعتبار

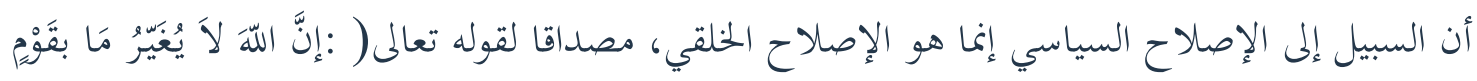

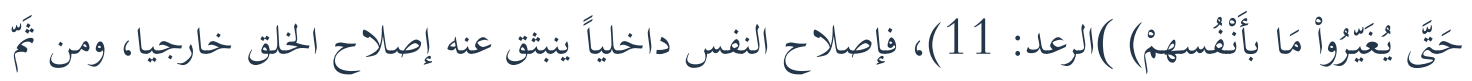
إصلاح السياسة، وينظر محمد عبده للسلطة السياسية على أغها "سلطة مدنية من جميع الوجوه، والحاكم مدني من جميع الوجوه(...)، وأن الأمة هي صاحبة القرار في تنصيبه وخلعه،" وهو بذلك يردّ على الشبهة القائلة بأن التزام الأمة بشريعة الإسلام إنما يهوّل السلطة لديها إلى سلطة دينية، مقارنة بالمفهوم السائد في التجربة الغربية، المقترن بادعاء التفويض الإلهي واستمرار احتكار السلطة؛ ولذلك يقول: "من أصول الإسلام: قلب السلطة الدينية، والإتيان عليها من أساسها (...) فلم يدع الإسلام لأحد بعد الله ورسوله 
سلطاناً على عقيدة أحد، ولا سيطرة على إيمانه (...) فليس في الإسلام ما يسمى عند قوم "بالسلطة

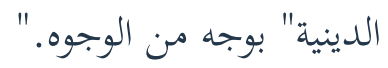
كذلك يدعو في كتاباته إلى إيجاد هيئة تقيد سلطات الحاكم "فالإمام محمد عبده من دعاة الشورى، وله في هذا الموضوع آراء سديدة، تدل على تبصّر وعمق عظيمين،" وكان متدرجا في هذا الأمر، إذلم يدع إلى إنشاء برلمانات في العالم الإسلامي، إلا إذا هيأ الناس لذلك، فقد كتب مقالة في "الوقائع" بتاريخ 4 إبريل 1881، تحت عنوان "خطأ العقلاء" يقول فيها: "فالحكمة أن تُفظظ للأمة عوائدها المقررة في عقول أفرادها، ثم يُطلب بعض تحسينات فيها، لا تبعد عنها بالمرة، فإذا اعتادوها، طُلب منهم ما هو أرقى "بالتدريج" (...) أما إذا وُضع لهم من الحدود ما لمُ يصلوا إلى كنهه، أو كُلّفوا من العمل ما لمُ يُعوّدوه، رأيتهم يتخبطون في السير؛ لخفاء المقصود عنهم (...)، فيمكن أن يخرجوا عن حالتهم الأولى، ولكن إلى ما هو أتعس منها بحكم الاستعداد القاضي عليهم بذلك؛" فالتكليف بما لا يعقله المكلّف هو من التكليف بما فيه مشقة، وهو مرفوض شرعاً، كما هو مقرر عند الأصوليين. ويدعو محمد عبده، إلى حين تحقق القبول العام لدى الجمههور بالإصلاح، إلى وجود "المستبد العادل"، إذ يذكر في مقالة له بعنوان "إنما ينهض بالشرق مستبد عادل" أن من صفاته: "أنه مستبد يُكره المتناكرين على التعارف، ويُلجئ الأهل إلى التراحم (...)، فهو لهم أكثر مما هو لنفسه (...) ويتمكن أن يصنع في خمس عشرة سنة ما لا يصنع العقل وحده في خمسة عشر قرنا." وقد انتقد هذا الرأي كثير من المفكرين، منهم الأمير "شكيب أرسلان" حيث قال: "إن الاستبداد لشر مطيّة تمتطيها الحكومة المستبيحة لنفسها التطوّح في البغي والجور والعتو. ولكن بعضهم يقول: هناك "المستبد العادل" النازل من الرعية منزلة الأب من الأسرة (...)، وإنما جميع ذلك وهم وخيال لا ظل لمما في الحقيقة، إذ قليل تم قليل هو "المستبد العادل" الذي صدق خبره (...)، زد على ذلك فإن المستبد العادل، ولو كان على حسن عمل واستقامة مسلك، فلا يكون خالصا من طائفة من العيوب والشوائب." ويظهر رفض محمد عبده للاستبداد من خلال فتوى سياسية في إحدى مقالاته بجريدة "الوقائع"، والتي كانت تحت عنوان "الشورى والاستبداد" بتاريخ 12 ديسمبر 1881م، ذكر فيها: إن الاستبداد المطلق منموع، منابذ لحكمة الله في تشريع الشرائع، ومعاند كل المعاندة لصريح الآيات الشريفة، والأحاديث الصحيحة الآمرة بإتباع أحكام الكتاب العزيز، والأخذ بالسنة الراشدة. ومن البديهي أن نصوص الشريعة لا تقوّم 
الحاكم بنفسها، فإها ليست إلا عبارة عن معاني أحكام مرسومة في أذهان أرباب الشريعة وعلمائها، فلابدّ من وجود أناس يمققون بمعانيها، ويظهرون بمظاهرها، فيقوّمونه عند انخرافه عنها، ويخضونه على ملازمتها، ويشثونه على السير في طريقها، وما لا يتم الواجب المفروض، وهو التقيد بالشريعة، إلا به فيكون واجباً، على حكم القاعدة عند فقهاء الشرع "ما لا يتم الواجب إلا به فهو واجب"، وقالوا: إن هذه الطائفة يجب تأليفها من أفراد الأمة، وجوباً كفائياً، على معنى أها إن لم تقم فيهم أثمت أفراد الأمة بجملتها، واستحقت العقاب برمتها، فقد "فرض" الله على الأمة الإسلامية أن تقوم منها أمة -أي طائفة- وظيفتها الدعوة للخير، والأمر بالمعروف والنهي عن المنكر، حفظاً للشريعة من أن يتجاوز حدودها المعتدون، وصوناً لأحكامها من أن يتعالى عليها ذوو الشهوات، فلم يجعل الله الشريعة في يدي شخص واحد يتصرف فيها كيف شاء، بل

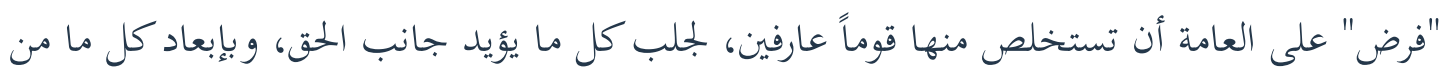
شأنه أن يحدث خللاً في نظامه، أو انحرافاً في أوضاعه العادلة. وبعد أن ذكر أدلة شرعية عدة قال: فتألف من مجموع هذا: أن الشورى واجبة. وهو يرى أن الشورى هي الأساس في الحكمم، فمقام الرياسة يختار بالمشاورة، لكل عمل وكل بلاد، بما يؤدي إلى اختيار من يكونون أكفاء للقيام بالواجب عن الأمة، فتكون أعمالهم مؤدية إلى مقصد الأمة العام، فيحقق هذا النظام رقابة وسيطرة العامة على الخاصة، فتحاسبها على تفريطها، ولا تعيد انتخاب من يقصر في عمله.

ولذلك فهو يعتقد بوجوب معرفة الأمة "علم السياسة" انطلاقاً من قوله تعالى (وَلْتَكُنْ مّنكُمْ أُمَّةُ يَدْعُونَ إلَى

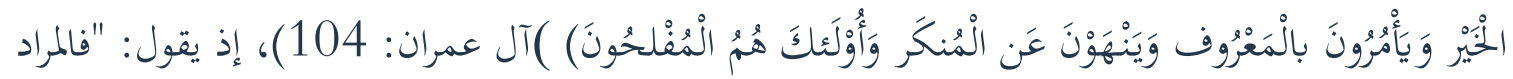
بعلم السياسة: العلم بحال دول العصر، وما بينهما من الحقوق والمعاهدات، وما لها من طرق الاستعمار، فالأمة التي تؤلف للدعوة في بلاد المسلمين المستقلة، لا يتيسر لها ذلك إذا لم تكن عارفة بسياسة حكومة تلك البلاد، والسياسة هذا المعنى لم تكن في عصر الصحابة."

ومع ذلك، فمحمد عبده يرى وجوب طاعة أولي الأمر بشروط، ويشرح ماهيتهم عند تفسيره لقوله تعالى (يَا

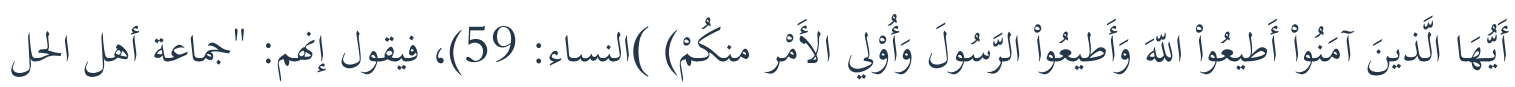
والعقد من المسلمين، وهم الأمراء والحكام، والعلماء ورؤساء الجند، وسائر الرؤساء والزعماء، الذين يرجع إليهم الناس في الحاجات والمصالح العامة. فهؤلاء إذا اتفقوا على أمر أو حكم، وجب أن يطاعوا فيه، بشرط 
أن يكونوا: منا، أي من المسلمين، وأن لا يخالفوا أمر الله ولا سنة رسوله التي عُرفت بالتواتر، وأن يكونوا مختارين في بحثهم في الأمر واتفاقهم عليه، وأن يكون ما يتفقون عليه من المصالح العامة، وهو ما لأولي الأمر سلطة فيه ووقوف عليه. وأما العبادات وما كان من قبيل الاعتقاد الديني، فلا يتعلق به أمر أهل الحل والعقد، بل هو مما يُؤخذ عن الله ورسوله فقط، ليس لأحد فيه إلا ما يكون في فهمه. فأهل الحل والعقد من المؤمنين إذا أجمعوا على أمر من مصالح الأمة، ليس فيه نص عن الشارع، مختارين في ذلك، غير مكرهين عليه بقوة أحد ولا نفوذه، فطاعتهم واجبة، ويصح أن يقال: هم معصومون في هذا الإجماع." رابعاً: الانتقادات التي وُجهت لمحمد عبده: 1. 1 آراؤه السياسية:

لقد جرّت عليه الآراء السياسية التي ظهرت في كتاباته كثيراً من النقد؛ ذلك بأن من حكمه المشهورة التي أصبحت مثلاً سائراً قوله: "ما دخلت السياسة في شيء إلا أفسدته"، "فإن شئت أن تقول: إن السياسة تضطهد الفكر أو العلم أو الدين، فأنا معك من الشاهدين، أعوذ بالله من السياسة، ومن لفظ السياسة، ومن معنى السياسة، ومن كل حرف يُلفظ من كلمة السياسة، ومن كل خيال يخطر ببالي من السياسة، ومن كل أرض تُذكر فيها السياسة، ومن كل شخص يتكلم أو يتعلم أو يجدّ أو يعقل في علم السياسة، ومن ساس وسائس وسوس." في حين يدافع عنه تلميذه رشيد رضا قائلاً: "وغرضه من ذم السياسة، ومن غي العاملين من المسلمين عنها، وإرشادهم بأن يكونوا في عملهم بمعزل عن تأييدها أو مقاومتها: هو أن السياسة في جميع بلاد المسلمين استبدادية جائرة (...) فتأييد سياستهم بالعلم والدين إفساد لمما، ومقاومتهم بمما عرضة لمنع إقامتهما، والتنكيل بأهلهما، فالطريقة المثلى اجتنابها، ومداراة أهلها، وإقناعهم بكل وسائل الإقناع الممكنة بأن الإصلاح العلمي أو الديني المطلوب: هو خير لبلادهم ورعاياهم، ونافع لم أو غير ضار

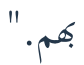
وقد انتقده محقق أعماله محمد عمارة في كلام طويل راداً على مذهبه، هذا بعضه: "فموقف "حممد عبده" من السياسة، هو موقف يرحب به المحتل؛ لأنه ليس مجرد "اعتزال" فردي للسياسة، وإنما هو دعوة لهجران العمل السياسي، والاستعاضة عنه بالعمل التربوي، وتعليق الآمال على التحرر بواسطته من الاحتلال، ولو بعد قرون (...)، إن المحتل كان أكثر ذكاءً وأبعد نظراً من محمد عبده (...) فإن آراءه في "الإصلاح الديني" 
و"التحرر الفكري" لا يمكن أن تنتصر تماماً، إلا بواسطة "نضال ثوري" ينهض بعبئه "جتمع ثوري" (...) فلابدّ أن تكون جزءاً من برنامج ثوري متكامل، يناضل أصحابه على مختلف الجبهات؛ لأن الأهداف التي سعى إليها "محمد عبده" هي في حقيقتها "مهام ثورية" (...)، والخطأ الذي وقع فيه الرجل: أنه سلك طريقا غير ثوري، كي يهقق بواسطته أهدافاً (...) ومهاماً ثورية، لابدّ لتحقيقها من أسلوب ثوري، ومناضلين ثوار." وإذا كان محمد عبده قد ناصر سلطة الفرد شريطة وجود قانون يهكم سلطة هذا الحاكم الفرد، فإنه بعد فشل جهوده في السياسة، هو وشيخه الأفغاني، ونفيهما، ثم عودته إلى مصر، لم يعد يشير إلى هذا القانون، ولا يطلب رقيباً على هذا المستبد إلا ذلك "العدل" الذي ينبع من ذاته وصفاته الخاصة؛ من أجل أن لا يُقال عنه إنه عاد إلى العمل في ميدان قرر هجرانه، بل إنه دعا أستاذه الأفغاني إلى هجر العمل في السياسة والاهتمام بالتربية، فنهره الأفغاني. كما أن لمحمد عبده آراء أخرى في: استقلال العرب، والوطنية، وغيرها. ومع أن في آرائه هذه الكثير من الخروج على المألوف، إلا أن البعض يرى أنه مؤسس ما يُدعى بـ "حزب الإصلاح الإسلامي المعتدل." وإذا

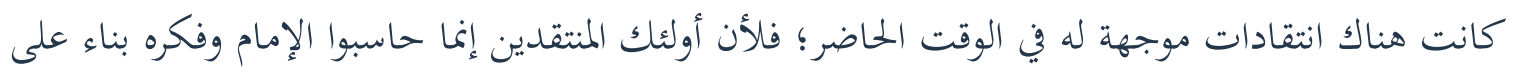
معطياتم الحالية، لا بناء على الواقع الذي وُجد فيه (وضع الاحتلال، والاستبداد، والجهل، والتخلف، ...إلخ). ولربما لو قُدّر له أن يعيش في وقت آخر غير الذي كان فيه لربما تبدلت آراؤه. لقد حاول محمد

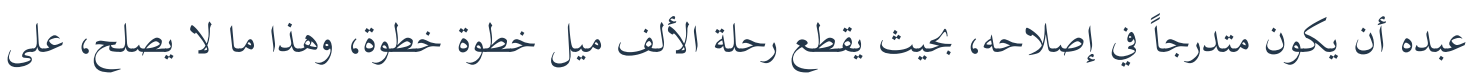
الأقل في الوقت الذي نعيشه، إذ نحن في عصر السرعة، الذي يتسارع فيه التقدم بنسبة أسية، مما يتطلب حرقاً للمراحل في الفكر الإسلامي، فإن لم يجار هذا الفكر ذلك التطور فإنه هو والعالم العربي والإسلامي سيبقون يرزحون تحت نير التخلف الحضاري إلى ما شاء الله. ولابدّ من الاعتراف، حتى لا يُظلم محمد عبده وفكره، بأن هاجسه كان، على الدوام، في جميع أعماله وكتاباته: محاولة سد الثغرة القائمة في المجتمع الإسلامي، والاعتراف بالحاجة إلى التغيير، وربط هذا التغيير بمبادئ الإسلام؛ لذلك اضطلع بمهمة ذات شقين، هما: إعادة تحديد ماهية الإسلام الحقيقي، والنظر في مقتضيات الإسلام الحقيقي بالنسبة إلى المجتمع

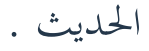

وعلى الرغم من أن خصومه، في مجالي الدين والسياسة، قد اشتركوا في تمييج الرأي العام عليه، وحاولوا 
إسقاطه من أعين الناس، من خلال رمي بعضهم له بالكفر الديني، والبعض الآخر بالكفر السياسي؛ فإنه قد أيقظ الشعور الديني، وأشعر المسلمين بوجوب القيام من مراقدهم لإصلاح نفوسهم، وإكمال نقصهم، وعدم الاعتماد على الفخر بالماضي، بل ببناء حاضرهم ومستقبلهم من جديد. كما دعاهم إلى تحكيم العقل في أمور الحياة كلها، حتى في الأمور الدينية، إذ الدين قد عُرف بالعقل، ولابدّ من الاجتهاد المعتمد على الدين والعقل معاً؛ للتمكن من مواجهة المسائل المستجدة في المدنية الحديثة، وإمكانية الاستفادة مما هو مفيد وذو أثثر جيد منها، فلم يكن محمد عبده من الذين يحاولون الإصلاح نظرياً، من خلال التأليف والخطابة والمقالات فقط، بل كان يحاول دائماً تحويل إصلاحه إلى أعمال منغمسة في الحياة الواقعية، بما يمكّن من تنفيذ برامجه الإصلاحية .

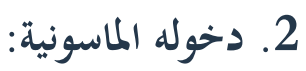

فالماسونية، كما يذكر أحد أعضائها: أكبر الجمعيات، وأغناها، وأشهرها، ولعلها أقدمها -أيضاً- على مدار التاريخ. وهي لا تفتح أبوابها لكل راغب، إنما تختار صفوة الناس، وتشترط لمن يريد الدخول فيها أن يكون:

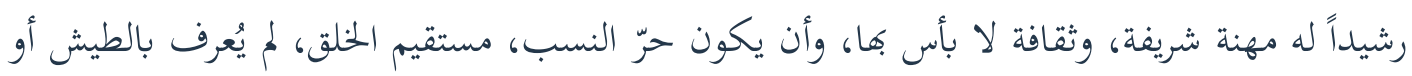
الخلاعة، وهي قد وضعت لنفسها دستوراً جذّاباً يخدع الكثيرين. ومراتبها ثلاث، هي: الماسونية الرمزية التي يجصل عليها أتباع الديانات المختلفة، ولها ثلاث وثلاثون درجة، والماسونية الملوكية أو العقد الملوكي التي أكثر أعضائها من اليهود، والماسونية الكونية التي تعدّ أرقى المراتب، وأعضاؤها من اليهود الخلّص . وهناك من يعدّ الماسونية اليوم، بعد أن بانت حقيقتها أهما "منظمة يهودية تظهر للحدمة اليهود من حين إلى لى حين (...) هذا في الباطن، أما في الظاهر فهي تظهر للسذج جمعية أدبية تخدم الإنسانية، وتنوّر الأذهان، وتنشر الإخاء، وتوطّد الحب بين الأعضاء، وتحثهم على فعل الخير والإحسان لإخوقم الحمتاجين، وهي في الحقيقة بعيدة كل البعد عن هذه الصفات، وشعارها الظاهري: الحرية، والإخاء، والمساواة. ولا شك أن هذه

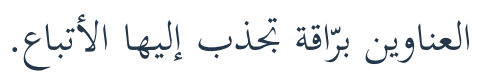
أما من يمق له دخول الماسونية فنوعان: أما النوع الأول: فجماعة المشاهير الذين لا تحوم حولهم شبهات، بكات والحاصلون على مراكز عليا في المجتمع، ومهمتهم ضمان السلامة للجمعية، وإبعاد الشبهات عنها، وخداع الآخرين بكم كي ينضموا لها. أما النوع الثاني فهي الجماعات المنجذبة بالأسماء اللامعة المنضمة للجمعية 
الذين يتم اختيارهم بدقة متناهية، بحيث يمكن تحصيل فوائد للجمعية من وراء انضمامهم إليها، بما يهقق أغراضها، في كشف بعض الأسرار أو ترويج بعض الشائعات الضارة. ويككن اعتبار محمد عبده من النوع الأول والذي دخل الماسونية بعد حصوله على العالمية، وتدريسه في الأزهر، فانضم للمحفل الماسوين

$$
\text { الإنجليزي (كوكب الشرق) التابع للمحفل الأكبر في انجلترا . }
$$

وقد كانت الماسونية في تلك الفترة "حسنة السمعة إلى حد كبير (...) ولم يكن الأثر السياسي لمن في قيادتا من اليهود قد ظهر بعد في قضايا الشرق العربي المصيرية." ثم إنه غادر مع الأفغاني "المحفل الماسوني البريطاني" إلى "الحفل الشرقي الفرنساوي" عندما وقفت الماسونية بمصر موقف اللامبالي بظلم النظام واستبداده، الذي يخدم النفوذ الأجنبي الزاحف على البلاد. وقد أملا أن يجدا في المحفل الماسوني الفرنسي ما هو خير للبلاد، وذلك قبل أن تتضح وحدة المحافل الماسونية في الأهداف، والتي علمها محمد عبده فيما بعد، إذ إنه ذمّ الماسونية قائلاً: "إن هؤلاء الماسون -دون تفرقة- رأوا من الحكمة أن لا يفرقوا بين الأديان في الدخول في جمعيتهم، بدعوى أها لا تمس الأديان، وإن كانت غايتها هدم جميع الأديان."

\section{3. انضمامه للحزب الوطني الحر وخروجه منه:}

فالحزب الوطني هو تنظيم شعبي، أسسه السيد جمال الدين الأفغاني في مصر سنة 1876م، وكان شعاره "مصر للمصريين"، أي لا للأجانب، ولا للشراكسة، وضم أعدادأكبيرة من التجار، والعلماء الأزهريين، والضباط العرب في الجيش، والمثقفين: كمحمود سامي البارودي الذي كان من أبرز قادة الحزب وأكثرهم ثقافة، وكان لدى الحزب، منذ بداية تأسّسه، تصور لمشروع إقامة دولة عربية مستقلة وموحدة وشعبية، رغم عدم إعلانه عن برنامج سياسي محدّد ومفصّل حول موضوع الوحدة. وقد يكون ما حال دون الإعلان عن مثل هذا البرنامج، أن الوضع السياسي لم يكن يسمح بمثل هذا الأمر؛ إذ سيكون الحزب آنذاك في مواجهة مع الحكام منذ بدايته دون أن يكون لديه الأهبة والإمكانية للردّ.

وقد انضم محمد عبده إلى الحزب منذ بدايته، بحكم التصاقه بالأفغاني؛ ولأن المبادئ التي كان يدعو إليها الحزب متوافقة مع رؤاه السياسية، إذ مما قيل عنه: لقد "هض هذا الحزب مطالباً للمصريين بحقهم في إصلاح خلقي، وحقهم في التعليم، وفي حياة سياسية حرة، وحقهم في أن يُشْهموا في حكم البلاد في ظل نظام دستوري برلماني. وما كان الحزب يريده من إصلاحات إدارية (...): تحرير الفلاح من عبوديته للباشاوات 
والأتراك، وإلغاء السُخرة، وتطهير العدالة، والاقتصاد في المالية، والتعليم العام الحديث، وفقاً لمبادئ حرية الفكر والمساواة أمام القانون والإخاء في العبادات."كما أن العمل ضمن جماعة مطلوب إسلامياً، إذ الأعمال الكبيرة تحتاج جهوداً جماعية، كما أن القرآن الكريم قد خاطب المسلمين في آيات كثيرة بصيغة الجمع ( يَا أَيهَها الَّنينَ آمَنُوا .)وقد قام محمد عبده بصياغة برنامج الحزب في ديسمبر 1881؛ وبعد ذلك انضم الحزب، ومحمد عبده معه، إلى الثورة العرابية بعد مظاهرة عابدين في 9 سبتمبر 1881م وحتى اهزامها، وعلى إثرها تيَّ نَفيه. وبعد عودته من المنفى، تغيرت آراؤه السياسية، فعدل عن آرائه السابقة، فقام الحزب بمحاربته لاختلافهما في أمور عدة: فكان محمد عبده يرى أن إصلاح التعليم أولاً، بخلاف الحزب الذي يرى أن الجلاء أولاً، وكان يعتقد بضرورة الاعتماد على العقل في ميدان السياسة، بخلاف الحزب الذي يرى الاعتماد على الشعور، ورأى أن الوضعية آنذاك لم تكن تسمح إلا بمسالمة الإنجليز، أما الحزب فيرى ضرورة المخاصمة العنيفة لهم، فهذه الأمور هي التي دفتت الحزب لرميه بالكفر السياسي. 4. 2. علاقتنه بالأوروبيين:

توطدت علاقة محمد عبده بالمثففين الأوروبيين فترة نفيه، من خلال أسفاره إلى أوروبا، خصوصاً مع (المستر ولفرد بلنت) (1922-1840م)، وهو كاتب وشاعر إنجليزي، تعرّف إليه محمد عبده في مصر قبل الثورة العرابية، ثم التقاه بعد ذلك في أوروبا ومصر، وأصبح الرجلان صديقين حميمين، وأثرت صداقتهما هذه في حياة كل منهما وكتاباقما. وكان "المستر ولفرد بلنت" مستشرقاً محظياً عند الساسة الإنجليز، وكانوا يطلبون آراءه في بعض الأمور السياسية، وقد قام بترشيح حممد عبده لشغل منصب الأوقاف لدى "السير إيفلين بارنج"، القنصل العام والمقيم البريطاني، وأعلى سلطة في ذلك الوقت بمصر. كما كان "بلنت" يأخذ برأي محمد عبده في كثير من المسائل ذات العلاقة بمصر، مثل: شكل الإدارة مع وجود الاحتلال، ونموذج الدستور المقترح في مصر، فردّ عليه محمد عبده بكتابين في الموضوعين، وهو يعلم أن هذه الكتب ستصل إلى الساسة الإنجليز وسلطة الاحتلال، فجعل آراءه فيهما بما يخدم قضية وطنه والإصلاح فيه. كما أنه حاول الاجتماع بكبار الحكماء والعلماء في أوروبا، فاجتمع بالفيلسوف الإنجليزي "سبنسر"؛ وكان يستهدف في مناقشاته مع المثقفين الأوروبيين شرح الصورة الصحيحة للإسلام، التي هي مشوهة لديهم، فاشترك في مناقشة حول هذا 
الموضوع مع المؤرخ الفرنسي (هانوتو)، كذلك كانت له علاقة ب(اللورد كرومر) الذي كان "أحد الذين شفعوا لمحد عبده عند (الخديوي توفيق) ليعود إلى مصر، بعد أن استوثق أن الإمام لم يعد يطمح إلى الثورة السياسية، وسيقصر عمله على "الإصلاح الديني" الذي تطمئن نفسه إليه، وهكذا كان." نتيجة لعلاقات محمد عبده بكؤلاء الساسة والمثقفين، نظّم (المستر بلنت) زيارة له لمقابلة أعضاء البرلمان الإنجليزي في لندن في النصف الأخير من شهر يوليو سنة 1884م. وكان هدف محمد عبده من هذه الزيارة: اكتشاف أفخاخ السياسة، وسبر أغوار المطامع الإنجليزية، ومطالبتهم بالجلاء عن مصر. وقد كانت مسوّغات ابتحاهه ناحية الساسة الأوروبيين: تلك الدسائس المتوالية والحملات المنكرة، الموجهة إليه من كل صوب في سعيه الإصلاحي، فكان لا محيص له من أن يتوجه إلى السلطات الإنجليزية، حيث سعى إلى (اللورد كرومر) وأقنعه بوجهته في الإصلاح (وكان إذ ذاك مفتياً لمصر)، فوجد منه العون الذي لم يجده عند (الخديوي عباس)، ولا عند شيوخ الأزهر. ثم إنه بعد عودته من منفاه إلى مصر وجد أن الإنجليز مسيطرون على كل أمور الدولة، فرأى أن يسالمهم كمنهج يهقق له غرضه في الإصلاح، إذ أنس منهم المساعدة على الإصلاح الديني؛ ذلك بأنه اعتقد أن مقاومة المستعمر لا تتيسر إلا بإنارة الشعب وتثقيفه الثقافة الدينية الصحيحة، رغم أن مثل هذه الخطوة ستضع عليه العديد من علامات الاستفهام أمام الشعب. فامتاز الإمام "بمذهب معتدل في السياسة إزاء الإنجليز، وهذا الذي جعله يهادن (كرومر) وسلطة الاحتلال، فلا يعتبر معركته المباشرة ضدهم، وإنما ضد العقبات التي تحول دون إصلاح الأزهر، والأوقاف، والمحاكم الشرعية، والتربية والتعليم، وهو الموقف الذي رضي عنه الإنجليز ورحبوا به؛ لأنه يتيح لهم الهدوء والاستقرار (...) وهذا الموقف من الإنجليز، هو الذي جلب عليه غضب أستاذه، وانقطعت المراسلات بينهما، بعد أن عنّفه الأفغاني أكثر من مرة، واتممه بالجبن." لقد رضي محمد عبده بالتعاون مع البريطانيين شريطة مساعدته في عمله من أجل التربية الوطنية، وعلى أن يكون بقاؤهم مؤقتاً، كما أنه كان مستعداً للتعاون مع (الخديوي توفيق) لو كان راغبا في أن يكون مستبداً عادلاً. ومن المؤكد أنه لولا تأييد (اللورد كرومر) له، لما بقي في منصبه في الإفتاء زمناً طويلاً، ولكان من اليسير إيباد الكثيرين غيره، من هم على أتمّ الاستعداد لإصدار فتاوى شرعية تبرر تصرفات الخديوي في الشؤون الدينية والمالية، فلم تكن مهادنة محمد عبده للإنجليز سذاجة، أو إرضاء لهوى، أو تحقيقاً لمصلحة 
شخصية، إنما لرؤيته إمكانية النهوض بالحركة الإصلاحية من خلال هذا الطريق. ذلك بأن محمد عبده قد مال، كما مال الفكر الإسلامي الحديث في مرحلة الدفاع، الذي يعدّ أحد مفكريه، إلى تحدئة الصراع المباشر مع الاستعمار، الذي أصبحت جيوشه في قلب العالم العربي، واتجه إلى الدعوة إلى إصلاح التعليم والمدارس والمناهج والمعاهد الدينية والمحاكم الشرعية، ولو بالتنسيق مع الحكام المستعمرين، على اعتبار أن لكل مرحلة خطتها، ولأن لكل تحدّ في الحياة استجابته الطبيعية. إن قيام محمد عبده بالإصلاحات العدة التي أنجزها مع وجود الاحتلال، ومع توفره على ما عُرف عنه من "إصلاح ديني"، يكون قد أسس مدرسة فكرية، ودينية، وعلمية، وتربوية، تتجه لمقاومة الاستعمار الغربي نفسه، لكن بطريق غير مباشر، وبما لا يقل وزناً عن الجهاد الذي يبذله النشاط القومي السياسي. وإذاكان البعض قد رأوه متخاذلاً حين تعهّد لكل من "كرومر "و"الخديوي توفيق" باعتزال العمل السياسي، إلا أنه قد لقدي التزم في أعماله بعد ذلك كلها خط "الاعتدال"، كما يصح وصفه بأنه أحد الزعماء الذين يصح وصفهم بأفم "زعماء وطنيون"؛ لأنه من زعماء مقاومة الاستعمار الغربي، ومعارضة النفوذ الأجنبي في دائرة العالم العربي والإسلامي؛ ولأنه واضع اللبنات الأولى في فكر "مقاومة القابلية للاستعمار،" لكنه اعتقد بأن مهادنة الإنجليز في وقته الراهن قد تعود ببعض الفائدة على المصريين. ولعل منبع مهادنته للإنجليز هو فهمه العميق لنفسية عدوه، إذ يقول: "إن من بين الأمم الأوروبية أمة تعرف كيف تحكم من ليس على دينها، وتعرف كيف تحترم عقائد من تسوسهم وعوائدهم، وهي الأمة الإنجليزية، إذ هي وحدها الأمة المسيحية التي تقدّر التسامح حق قدره، كما أن الإسلام السليم الخالي من البدع هو أستاذ الإنجليز، وعنه أخذوا هذه الحنلة (أي التسامح). فهو يرى أن طريقة التعامل معهم ينبغي أن يكون مدخلها هو إقناعهم، من خلال الحوار معظم عن طريق ما يعتقدونه من الأخلاق، وما رسخ في طباعهم، أو من جهة إقناعهم بما فيه مصلحة بحارية نفعية لهم، فمن هذين الطريقين كان محمد عبده ينجح في إقناع اللورد (كرومر) بكثير من المصالح الوطنية للبلاد. وكانت النظرة الثاقبة لمحمد عبده ترى "أن العمل لإخراج الإنجليز من مصر، عمل كبير جداً، ولابد في الوصول إلى الغاية منه: من السير في الجهاد على منهاج الحكمة والدأب على العمل الطويل، لقرون عدّة. لا أنه عمل صغير يكفي فيه الكلام في المجالس والكتابة في الجرائد." ولمج يكن يرى قطع الصلة بالغرب بقيام إحدى دوله باستعمار بلده؛ لأنه "كان متيقناً من تقدم الحضارة الغربية، 
وحاجة المسلمين إليها." لكن، إذا كان محمد عبده قد درس الاستعمار ونفسيته، فإن هذا الاستعمار أيضاً- قد درسه دراسة وافية هي التي جعلت اللورد (كرومر) يقول عن محمد عبده: إنه الأمل الرئيسي للإصلاح الإسلامي في مصر. كما يمكن استخلاص صورة وافية للإمام، وما كان عليه في شبابه وكهولته وشيخوخته من خلال كتابات "بلنت" ويومياته.

ومن الفتاوى التي تظهر مدى قبول محمد عبده بالتعاون والتحالف مع غير المسلمين، رده على سؤال جاءه من الهند نصه: ما يقول السادة العلماء في جماعة من المسلمين يقّرون أفم على عقيدة أهل السنة والجماعة(...) إلا أهم مع ذلك يستعينون بالكفار وأهل البدع والأهواء لنصرة الملة الإسلامية، وحفظ حوزة الأمة المحمدية، وجمع شملهم واتحاد كلمتهم، فهل مثل هذه الاستعانة تجوز شرعاً؟ وهل لها نظير في القرون الثلاثة الفاضلة المشهود لما بالحير؟ وهل يجوز لأحد من المسلمين أن يسعى في التنفير من صحبتهم؛ نظراً لاستعانتهم بالكفار، وأهل البدع والأهواء، لمثل هذه المصالح العامة؟ وما حكم من يرميهم مجرد هذه الأعمال بالكفر والتضليل وسوء الاعتقاد والخروج عن أهل السنة والجماعة؟. وكانت منهجية الإمام في الرد على هذا السؤال بإيراد أجوبة أفاضل علماء الشافعية والمالكية والحنابلة، ثم جواب الشيخ محمد الطوخي (الحنفي)، وكل هذا مُدعَّماً بأدلنه، وبعد ذلك ذكر رأيه قائلا: هذا ما ذكره هؤلاء الأفاضل، ثم نقول: المطّلع على ما نقله حضرات الأساتذة من علماء الجامع الأزهر من نصوص الكتاب والسنة وأقوال الأئمة والعلماء من أهل المذاهب الأربعة، يعلم حق العلم أن ما يفعله أولئك الأفاضل، دعاة الخير، هو الإسلام، ومن أجلّ مظاهر الدين، وأن الذين يكفروغم أو يضللوفم، هم الذين تعدوا حدود الله، وخرجوا عن أحكام دينه، وبعد أن ذكر أدلة أخرى زائدة قال: فقد قامت الأدلة من الكتاب والسنة وعمل السلف على جواز الاستعانة بغير المؤمنين، وغير الصالحين، على ما فيه خير ومنفعة المسلمين، وأن الذين يعمدون إلى هذه الاستعانة لجمع كلمة المسلمين، وتربية أيتامهم، وما فيه خير لهم، لم يفعلوا إلا ما اقتضته الأسوة الحسنة بالنبي -عليه السلام- وأصحابه، وأن من كفّرهم أو فسّقهم، فهو بين أحد أمرين: إما كافر، أو فاسق، فعلى دعاة الخير أن يجدّوا في دعوتم، وأن يمضوا في طريقهم، ولا يجزهم شتم الشاتمين، ولا يغيظهم لوم اللائمين، و الله كفيل لهم بالنصر إذا اعتصموا بالحق والصبر، والله أعلم، ويككن اعتبار هذه الفتوى هي أشهر فتاواه السياسية. لقد أثار تعامل محمد عبده مع الساسة والمثقفين الأوروبيين كثيراً من سوء الفهم لفكره، ومن ذلك ما قاله 
أحدهم: إن الأمور ظلت مختلطة في ذهن محمد عبده، بوصفه أحد قادة النهضة في تعامله مع الغرب، من ناحية إشكالية ازدواجية الثقافة والسياسة ضمن مفهوم الغرب، وفي كون الغرب ينطوي على كل من الثقافة والسياسة معاً، وعدم إمكانية انفصالمما عنه، وإن كان كل منهما يسير في ابتحاه مخالف للآخر لديه، فبذلك تصبح عملية الاتصال الظاهرة بالغرب هي عملية مركبة ومعقدة. وعلى كلٍّ، فقد كان من نتائج أسفار محمد عبده وتنقلاته في أوروبا، واجتماعه بأهل الرأي فيها من المثقفين والساسة أن قوي الأمل لديه في إصلاح أحوال المسلمين؛ ذلك بأنّ بلاد أوروبا ارتقت ارتقاء عظيما في العلوم، والصناعات، والسياسة، وغير ذلك، ومن يذهب إليها يتأثر بارتقائهم، فتنهض همته. وكان يقول عندما يهم بالسفر إلى أوروبا: إني ذاهب لأجدد نفسي. ويمكن القول إن الثنائي "الأفغاني-محمد عبده" قد شكّالا، فاية القرن التاسع عشر، ما يصح أن يُطلق عليه "الفكر الإسلامي المقاوم للغزو الأجنبي العسكري والسياسي والفكري"، فقاما معاً بالتصدي لكل محاولات النيل من الإسلام، بوصفه ديناً وهوية حضارية للأمة، وكانا على رأس المدافعين عن وحدة الأمة الإسلامية في وجه الغزو الأجنبي، ومحاولاته لتفتيت الامبراطورية العثمانية، والقضاء على الحلافة الإسلامية. كما أفما وقفا سداً منيعاً للدفاع عن الإسلام ضد محاولات التشويه التي كان يقوم بها المستشرقون الأوروبيون لإظهار الإسلام كعدو للعلم والتقدم، فإذا كان محمد عبده قد أصاب في اجتهاده فله أجران، وإن أخطأ فله أجر واحد. 5. 5. اشتراكه في الثورة العرابية:

الثورة العرابية: هي تلك الحركة التي قام بها "أحمد عُرابي باشا" وأعوانه، بغرض مساندة الضباط الوطنيين، والقضاء على عوامل الاضطهاد الذي كانوا يعانونه من الضباط الأتراك والشراكسة المتعالين، ظناً منهم أفم طبقة أعلى من الطبقة المصرية، وكذلك لرد حقوقهم المشروعة في المناصب والرتب العسكرية. وكانت تحقيق هذه المطالب هي غاية ما يرجوه زعماء الثورة بادئ الأمر، إلا أن الحركة تطورت شيئاً فشيئاً لتشمل كل طبقات الأمة، محاولة التخلص من الحلكم الاستبدادي، وداعية إلى تقرير مبادئ العدل والحرية؛ مما جعل من الثورة العرابية أهم مظهر للسياسة المصرية في الربع الأخير من القرن التاسع عشر. وكان محمد عبده أول أمر الثورة كارهاً لها، مُندّداً بزعمائها، إذ كان يعلم أها ستحبط عمله الإصلاحي الذي بدأه، بل كل إصلاح تعمله الحكومة أو تنوي عمله، كما أها ستمهد الطريق للأجانب للتدخل في شؤون 
البلاد والاستيلاء عليها، وقد كان في محاوراته مع "عرابي: يصرح بأن: أول ما يجب أن يُبدأ به هو التربية والتعليم؛ لتكوين رجال يقومون بأعمال الحكومة النيابية على بصيرة مؤيدة بالعزيمة، وأنه ليس من الحكمة أن تُعطى الرعية ما لم تستعد له، فذلك بمثابة تمكين القاصر من التصرف بماله قبل بلوغه سن الرشد، وكمال التربية المؤهلة والمعدة للتصرف المفيد، وأن الأمة لو كانت مستعدة لمشاركة الحكومة في إدارة شؤوها لما كان لطلب ذلك بالقوة العسكرية معنى، فما يطالب به رؤساء العسكرية الآن غير مشروع؛ لأنه ليس تصويراً لاستعداد الأمة ومطلبها. فمخالفة محمد عبده للعرابيين في أول حركتهم، إنما قامت على أساس أن حركتهم لم تكن ثورة شعبية بالمعنى الصحيح، وأن مقاصدها إنما كانت طائفية بحتة، ولا تتصل بترقية الأمة في بجموعها. كما أن محمد عبده كان يعتقد أنه لم يكن يخطر ببال "عرابي"، ولا من أحلامه، طلب إصلاح حكومة أو تغيير رئيسها، بل كان همه هو الأمن على مقامه، والانتقام من عدوه، والخصول على ما كان بيد الشراكسة من الوظائف العسكرية، بغرض التمتع بما كانوا يتمتعون به من مال ونفوذ. وكذلك فقد كان اعتراضه على "عرابي": أن عرابي نفسه كان يظن "بما كان يسمعه عن وجود بجالس نواب في الممالك الأوروبية، أنه لو كانت في البلاد تلك القوة النيابية، ولو أن حكومتها كانت حكومة شورية، لكانت الشورى أو مجالس النيابات عاصماً لحياته، حافظاً لحقوقه في وظائفه، ومأمناً يلجأ إليه إذا حوّم طائر الانتقام عليه." فكانت نظرة محمد عبده لعرابي: أنه "غرُّ ساذج، ينخدع للأجانب بما لا يصح أن يخفى على رجل متعلم في الدرجة الوسطى.

وقد ذكر محمد عبده من الأسباب الوجيهة، في نظره، لمعارضة الثورة العرابية: "أن (البارون درنج) (القنصل الفرنسي) لأسباب سياسية، و(الخديوي توفيق) لأسباب شخصية، كانا وراء الثورة على حكومة "رياض باشا؛" فانخدع عرابي بهؤلاء وبتأكيداتم ووعودهم له، "وانخدع كذلك بجواسيس الإنجليز، وكان يُطلع بعضهم على أسراره العسكرية، وهو لا يتصور وقوع الخيانة منهم؛ لأغم مسلمون، وقام في أحرج ساعة في الحرب تهرب فقضى وقته في الصلاة والأدعية والأذكار، ونسي واجب الجندي الصحيح، في أخذ الأهبة للمعركة، والاستعداد لمنازلة الأعداء،" فلعبت بالثورة أياد خارجية، كان محمد عبده على وعي بها، كما أنه كان يعلم من ملاحظته لوقائع التاريخ والأحداث "أن الثورة العسكرية في مصر قد تفضي لاحتلال أجنبي يذهب باستقلالها (...)، وذلك من سيرة الإنجليز في الاستيلاء على الممالك الهندية." 
كذلك نبع رفض محمد عبده للثورة العرابية، من كون "رياض باشا" (رئيس الحكومة) كان يسير في الإصلاح بخطى حميدة لا عيب فيها، حتى أن محمد عبده عَدّه "صورة حسنة للمستبد العادل،" وكان معروفاً عن "رياض باشا" آراؤه الحرة ضد الاستبداد أواخر عهد "الخديوي إسماعيل،" وإن كان محمد عبده معترضاً على سئ محاولته "تعميم العدل والمساواة بسرعة." كما أن من الأمور الإيجابية التي قام بها "رياض باشا"، في نظر محمد عبده: إلغاء نظام السخرة الشخصية (الخاصة والعامة)، والعدل في توزيع مياه النيل بين الأغنياء والفقراء، وإلغاء كثير من الضرائب، وإبطال الضرب بالكرباج في تحصيل الأموال، وإبطال الحبس في تحصيل الحقوق، وإصلاح نظام العسكرية، وإصلاح المحاكم، وغير ذلك كثير؛ ولهذا كان الحنديوي والأجانب من المشجعين للثوار على إسقاط هذه الحكومة التي خشوا منها على مصالحهم. وهناك من يرى أن محمد عبده، وإن لم يكن سبباً مباشراً في الثورة العرابية، فإن كتاباته ومقالاته الإصلاحية تبدو سبباً غير مباشر للثورة، مما هيأ له الطريق ليكون أحد رجالها، وإن كان ظهوره لم يبرز إلا في المرحلة الثانية من الثورة، فحوكم على أنه أحد أعمدة الثورة وزعمائها، خاصة أنه جاهر بخلع الخديوي . وعلى الرغم من أن محمد عبده كان إصلاحيا، ولم يؤمن بالثورة طريقاً لتحقيق فضة الشرق وبحديد الحياة فيه، وإنما عبر التربية والتعليم والاستنارة الفكرية، وكان موقفه من الثورة هو موقف المعارض؛ لكن ما دفعه للانضمام للثورة أنه نظر حوله فرأى أن الأمة بأسرها معها، ولم يبق إلا القليل مع "الخديوي توفيق" (والذي رأى محمد عبده عدم إمكانية الوقوف بجانبه بعد استعانته بالدول الأجنبية في إخماد الثورة)، فلم تعد القضية منحصرة في حزب، بل أصبح هو شأن الأمة كلها أمام إنجلترا . لقد كان محمد عبده ينهى عن الثورة ويسعى لمنعها، إلى أن نزل الجيش الأجنبي وسط البلاد محارباً لأهلها، فصار عوناً للأهالي على قتال عدوهم، وأصبح العرابيون يلجُؤون إليه في كثير من أمورهم، ولا يبرمون أمراً دون استشارته. وعندما ضُربت الإسكندرية بقنابل الأسطول الإنجليزي دعا محمد عبده إلى التطوع في صفوف الجيش المدافع عن مصر، وإمداده بالإعانات والتبرعات، وكتب بهذا الصدد مقالات في جريدة "الوقائع" تفيض بلاغة وحماسة، إذ رأى أن واجبه يحتمّ عليه أن يكون مع الأمة على الإنجليز وعلى الخديوي؛ وظل في مكانه من المسؤولية والقيادة مع الثوار حتى هزيمة الثورة في سبتمبر 1882م؛ نتيجة لأخطاء عرابي، وخيانة بعض المسؤولين المصريين. فتمَّ إقلاء القبض على زعماء الثورة، ومنهم ححمد عبده، وحُكم على عرابي 
بالنفي مدى الحياة في "سيلان"، وعلى محمد عبده بالنفي ثلاث سنين إلى "سوريا"، والتي امتدت فعلياً إلى

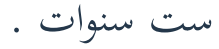

وقد رأى محمد عبده أن الثورة العرابية أحدثت فوائد عدة، أهها: شعور الشعب المصري، في المدن والقرى، بوجوده وحقوقه، وضعف ما كان مستحوذا على قلوب أهله من هيبة الأمراء والحكام؛ وبروز فكرة أن الحكومة الشخصية الاستبدادية إذا لم تسقط بقوة الأمة فإِها ولابدّ ساقطة بقوة الأجانب، وأنه لا قوة للدولة إلا بالأمة. ولو تم تحكيم المنطق في علاقة محمد عبده بالثورة العرابية لكان القول إنه لا ينغمس فيها مطلقاً، لا في أولها ولا آخرها؛ لأنه لا يؤمن بالحكم النيابي السريع؛ ولأنه يناصر "رياض باشا"؛ ولأنه لا يرضى أن تكون الثورة بيد العسكريين، ولأنه يكره "عرابي باشا"، ويعتقد أنه شهم في الكلام، ضعيف في الحرب، ويحتكم إلى المنامات أكثر مما يحتكم إلى العقل. لكن محمد عبده، مع مناهضته للثورة في أولها، أصبح مشايعاً لها في آخرها؛ لأن أمرها لم يصبح أمر حزب أمام حزب، بل هو أمر الأمة أمام الإنجليز، فلابدّ أن يكون مع أمته .

\section{6. تأسيس "جمعية التأليف والتقريب بين الأديان" السياسية السرّية :}

فقد قام محمد عبده بتأسيس جمعية التأليف والتقريب بين الأديان في بيروت، بمشاركة "ميرزا باقر" الفارسيّ الذي يُقال إنه تنصّر ثم أسلم، وكان الغرض من إنشائها: التأليف بين الإسلام والمسيحية واليهودية (الأديان السماوية الثلاثة)، والعمل على إقامة الوئام بين أهل هذه الأديان، والتعاون على إزالة ضغط الغرب على الشرق. فلها، إذن، هدفان: أحدهما: ديني، والآخر: سياسي. كما انضم إليها "مؤيد الملك"، أحد وزراء إيران، و"حسن خان" مستشار السفارة الإيرانية في الأستانة، إضافة إلى بعض اليهود الإنجليز، و"القس تس إسحاق تيلر" راعي الكنيسة الإنجليزية الذي حاول نشر أفكار الجمعية في انجلترا. وهناك رأي بأن من أهداف الجمعية "دعوة غير المسلمين إلى الدخول في الإسلام، بعد الإقناع بالحجة والاعتقاد الصادق بما نزل على "محمد" -صلى الله عليه وسلم- من الشرائع والأحكام." لكن هذا لم يكن مبداً واضحاً للجمعية، وإن كان لربما في ذهن محمد عبده. كما أن الملاحظ على أهداف ولى الجمعية أن الأثر الغالب فيها لن يكون لصالح الإسلام، في ذلك الوقت الذي يعاني فيه المسلمون الضعف والتخلف، في حين أن الغلبة هي للعالم المسيحي، هذا من الناحية الدينية. أما من الناحية السياسية فسيحكم 
الجمعية الطرف الأقوى سياسياً، وليسوا هم المسلمين على أيّ حال. وقد كان من أثر إنشاء هذه الجمعية، في رأي البعض، أن أمر السلطان العثماني بعودة الإمام إلى مصر؛ خوفاً من أن تُسلم "الملكة فكتوريا" بعد معرفتها شيئاً عن الإسلام بوساطة الجمعية، فتصبح بذلك أقوى شخصية إسلامية، وتحتل مكانة السلطان

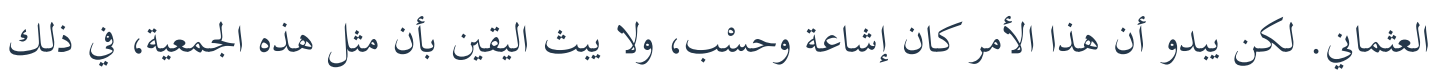

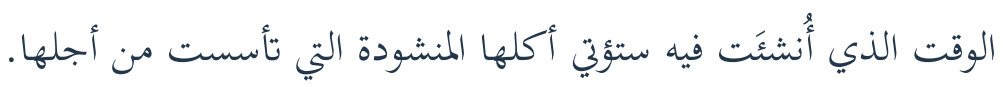
7. تأسيس "جمعية العروة الوثقى" السرّية وجريدتما:

وقام الأفغاني مع محمد عبده بتأسيس جمعية (العروة الوثقى) بباريس. ويمكن اعتبارها الامتداد أو البديل عن الحزب الوطني الحر الذي أسسه الأفغاني بمصر قبل الثورة العرابية، ثم ذهبت ريحه مع فشل العرابيين. وقد يكون أمل الأفغاني من إنشاء هذه الجمعية إكمال الرسالة التي كان يبتغيها من إنشاء الحزب. فقد كان هناك غرضان من إنشاء الجمعية: أحدهما قريب، والآخر بعيد: وقد بتلى الغرض القريب في إنقاذ مصر والسودان من الاحتلال، أما الغرض البعيد فتمثل في إعادة الحكم الإسلامي، وهداية الناس إلى ماكان عليه هذا الحكم من الطهارة والعدل والكمال في العصر الأول، وذلك من خلال تأسيس حكومة إسلامية على قاعدة الخلافة الرائدة في الدين، وما تقتضيه حالة العصر لمجد الإسلام من أمور الدنيا، وما يتبع ذلك من إنقاذ المسلمين وغيرهم من الاستعمار المذل لمم .

وقد تزعَّم الأفغاني الجمعية، التي أصبح لها فروع سرية في غالبية البلدان الإسلامية، في الهند، وأفغانستان، ومصر، وكثير من بلدان الشرق، ومارس محمد عبده خلال هذه الفترة نشاطات سرية متعددة، كما تنقل كثيراً في أوروبا، وزار عدداً من البلدان الشرقية التي كانت سرية في مجملها؛ لخدمة أهداف الجمعية، إذ دخل إلى مصر خلسة عندما اشتدت ثورة المهاي في السودان، ثم عاد إلى باريس لممارسة القيادة السرية للجمعية في حالة غياب الأفغاني، إذ كان نائب الرئيس. ومبادئ هذه الجمعية غير معروفة؛ نظراً لسريتها، ومن المؤكد أخها ضمت أشخاصاً ذوي مكانة ورأي في عدد من بلاد الإسلام المختلفة؛ لتحقيق حلم الأفغاني بإنشاء دولة

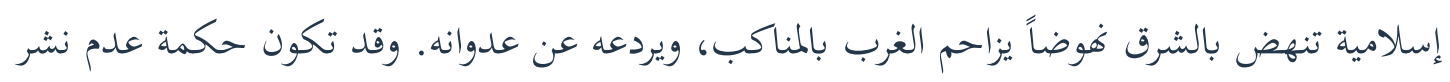
مبادئ الجمعية، الخوف من التضييق عليها، ومحاصرتحا قبل أن تبدأ، كما حدث مع جريدقا. وقد أُنشئت جريدة "العروة الوثقى" التي تمثل فكر الجمعية من مال الجمعية في باريس، وعندما وقف يُحرّرو 
الجرائد الإنجليزية الكبرى على نية إصدار الجريدة، أخذقم الحلدة، وأنذروا حكومتهم بما ستحدثه هذه الجريدة من أثر سلبيّ على سياسة الإنجليز ونفوذها في البلاد المشرقية، وألحوّا عليها أن تبذل كل مسعى ووسيلة لمنعها من الدخول إلى البلاد الهندية والبلاد المصرية، وهذا الذي كان. فقد كان هدف الجريدة هو: المدافعة عن حقوق الشرقيين عموماً، والمسلمين خصوصاً. وانحصرت مقاصدها في أربعة أمور، هي: الجامعة الإسلامية، والرابطة الشرقية المرتبطة بالجامعة الإسلامية، والمسألة المصرية، والمسألة السودانية . فكان الغرض من الجامعة الإسلامية: إحياء جميع الشعوب الإسلامية، ودفعهم للتعاون لرد استعباد الغرب لهم، والعمل على الاستقلال الذاتي للبلاد الإسلامية، والجمع بين الرابطة الإسلامية والرابطة الوطنية في البلاد التي تتعدد فيها الملل، بحيث لا تشعر الأقليات غير المسلمة بأدنى امتعاض أو شكوى من الإصلاح الإسلامي. أما بالنسبة للمسألة المصرية فعملت الجريدة في مقالاتا على الدفاع عن مصر، والسعي لإنقاذها من الاحتلال الإنجليزي، بل إقناع الإنجليز أنفسهم بالجلاء عن مصر، من خلال انتهاج وسائل عدّة، أبرزها: إثارة العالم الإسلامي، عبر تمييج مصر والهند والرأي الإسلامي العام على الاحتلال الإنجليزي، وحث الدولة العثمانية على العمل لإخراج الإنجليز، عبر طريقي السياسة والقوة معا، ومحاولة إقناع فرنسا بمساعدة مصر والدولة العثمانية على إخراج الإنجليز، على اعتبار أن في ذلك حفظاً لمصالحها الاقتصادية ونفوذها السياسي والأدبي، وإغراء روسيا بالزحف على الهند، اعتماداً على نفوذ الدولة العثمانية الديني في الهند، وعلى مساعدة دولة الأفغان وإيران لتحقيق ذلك، عبر اتفاق يعقد بينهما إذا أمكن، وإلا انفردت بالعمل. أما بالنسبة للمسألة السودانية فقد اعتمدت الجريدة على تخويف الإنجليز من الدعوة المهدية بالسودان والثورة التي تمثلها، وأن الجيش الإنجليزي إذا اهزم أمامها فإن ذلك سيوثر على هيبته أمام مستعمراته الأخرى المنتشرة في العالم. لقد كان محمد عبده هو الكاتب ورئيس التحرير، وكان الأفغاني هو المفكر؛ ولذلك يقول رشيد رضا: أنبأني الأمير شكيب أرسلان أنه سمع محمد عبده يذكر أن كل الأفكار التي في (العروة الوثقى)، هي للأفغاني، وأنه ليس له منها فكرة واحدة، باستناء ما قام به من صياغة العبارات. وكان مقر الجريدة وإدارتا عبارة عن حجرة ضيقة في سطح منزل من المنازل القائمة بشارع "سيز" القصير والقريب من ميدان "المادلين" في باريس، غير أن هذه الحجرة الصغيرة كانت ملتقى العديد من الشخصيات الشرقية والغربية، واشتغل فيها

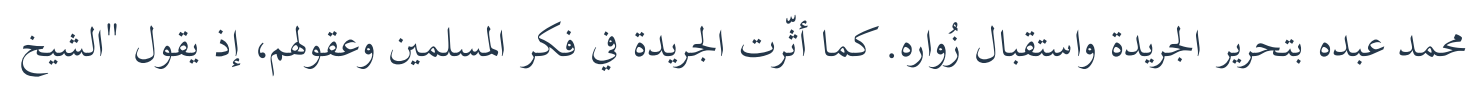


حسين الجسر" عالم سوريا الذي جمع بين العلوم الإسلامية ومعرفة حالة العصر السياسية والمدنية: ماكان أحد يشك في أن جريدة "العروة" ستُحدث انقلاباً عظيماً في العالم الإسلامي لو طال عليها الزمان، وقال الزعيم "سلمان الكيلاني"، أحد زعماء المسلمين أصحاب النفوذ في قبائل العراق المسلحة التي لم تكن خاضعة للدولة العثمانية، ومن أصحاب النفوذ الروحي في الملايين من مسلمي الهند: كلما جاء عددٌ منها يوشك أن تقع ثورة من تأثير هذه الجريدة .

ونتيجة الخوف من جريدة العروة، سواء أكان واقعاً أم مُتوقعاً، "انعقد مجلس الوزراء المصري في القاهرة المحكوم من قبل الإنجليز - (...) ثم أصدر قراره إلى وزارة الداخلية المصرية، بأن يشتد في منع هذه الجريدة من الدخول للأقطار المصرية (...)، فصدر أمر وزارة الداخلية، وأعلن في الجريدة الرسمية صورة الأوامر: أن كل من توجد عنده "العروة الوثقى" يُعرّم مبلغاً من خمسة جنيهات مصرية إلى خمسة وعشرين جنيهاً، وهي غرامة جسيمة، ربما دعا إليها عسر المالية المصرية ببركة تصرّف الإنجليز في مصر." وقد أثرّت هذه المضايقات وغيرها على الجريدة، فلم تستطع أن تكمل مسيرقا لتحقق أهدافها، إذ لم تعش أكثر من ثمانية شهور، فصدر منها ثمانية عشر عدداً، أولها: في 15جمادى الأولى 1301هـ/13مارس 1884م، وآخرها: في 26 ذي الحجة 1301هـ/17 أكتوبر 1884م. وهنا يتبادر السؤال إلى الذهن: هل كان يمكن لجريدة، مهما كانت، أن تحقق الأهداف العظيمة كالتي وضعت لجريدة "العروة الوثقى"؟ أم أها كانت بحاجة للدعم بوسائل أخرى؟. ولعل وعي محمد عبده والأفغاني معاً بهذا الأمر، هو الذي دفعهما إلى جعل الجريدة هي العمل الظاهر لعمل خفيّ آخر في السّر من خلال "جمعية العروة الوثقى"، انطلاقاً من فهمهما العميق لأوامر الدين، وأقوال النبي -عليه السلام- الداعية لأخذ الحيطة والحذر والكتمان إلى حين تمام الأعمال، منها قوله "استعينوا على قضاء الحوائج بالكتمان، فإن كل ذي نعمة محسود." فكان لابدّ من اجتماع العلم الظاهر مع الخفي، إضافة إلى اجتماع الفكر والعمل، ضمن ضوابط الشرع وفقهه العميق. وهذا الدرس هو ما يمكن للحركات الإصلاحية انتهاجه اليوم، بإنشاء وسائط إعلامية من جرائد وغيرها ينشرون من خلالها أفكارهم للجمهور . 8. - عمله في مجلس شورى القوانين: بعد تعيين محمد عبده عضواً دائماً في مجلس شورى القوانين، انتقل به المجلس من حال إلى حال. وقد 
خصص محمد عبده ججلّ وقته في عمله في هذا المجلس للتربية والإصلاح كما كان يفهمه، فلم يكن يعدّ نشاط المجلس عملاً سياسياً، بل جزءاً من مهمة "التربية السياسية"؛ لذا لم يرغب في أن تزداد صلاحياته؛ ذلك بأن محمد عبده فرّق بين الاستبداد والاستبداد المطلق، فرفض الاستبداد المطلق، في حين أنه طالب بوجود "المستبد العادل"، كما رأى أن الاستبداد لا يمكن رفعه إلا بعد تكوين رأي عام يستحق الحياة السياسية الحرة. وقد اعترض بعض المفكرين على محمد عبده في رأيه بخصوص مجلس الشورى، ومنهم رشيد رضا الذي قال له: لو صرفت مثل هذه الأوقات الطويلة في أعمال المجلس إلى الكتابة والتأليف لكان ما تكتبه هداية لهذه الأمة باقية ما بقيت الأمة، فرد عليه محمد عبده: إن الغرض الأول من العمل في المجلس، هو التعاون مع الأعضاء على الجد والاهتمام بالبحث في الأمور العامة ومصالح البلاد، وتربية الرأي العام في الأمة ليكون ذلك إعداداً لنفوس طائفة منها، للفصل في الأحكام بالشورى، فإذا ارتقت هذه الملكة في الهيئة الحاضرة للمجلس، فإنها تنتقل منها إلى الهيئة التي تخلفها، ويكون ذلك جرثومة من جراثيم الإصلاح في البلاد، فعند ذاك علم رشيد رضا أن محمد عبده لم يترك مذهبه في الإصلاح، وذلك بانتهاجه أسلوب التربية العملية

لقد كان محمد عبده من دعاة الشورى، وله العديد من الآراء والمقالات هذا الشأن، وطريقه في تحقيق الشورى هو التدرج، إذ كان يرى أن أفضل القوانين، وأعظمها فائدة: هو القانون الصادر عن رأي الأمة، وهذا القانون هو المستحق لوصف القانون، وهذا ما لم يكن متيسراً بعد في رأيه. وكان ينظر لمجلس شورى القوانين، على أنه هيئة دستورية معصومة فيما تقرره من أحكام، إذا أجمعت عليها؛ لأهما مثثلة الأمة، والأمة

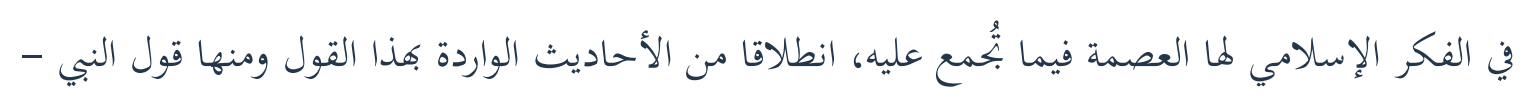
عليه السلام - "لا بتمتع أمتي على ضلالة." وكان في مطالبته إصلاح المجلس، يطالب -أيضاً -بإصلاح المحاكم الشرعية، دون التطرق إلى الإصلاحات السياسية؛ نظرا لاتبّاعه منهج الإصلاح المتدرج، فكانت الإصلاحات السياسية هي آخر ما يطلبه. وقد قال "حسن باشا عاصم" في تأبين محمد عبده يوم ذكرى الأربعين من وفاته: عُيّن في مجلس شورى القوانين فكان إلهان -رحمه الله- عامل التوفيق بين المجلس والحكومة، وكان أهم غرض له من التعب الشديد في المجلس: تعويد الأمة على دقة البحث في أمورها، وتربية الرأي العام فيها. فلم يكن في وسع محمد عبده، وهو المصلح 
الديني، أن يقطع صلته بالتربية السياسية .

خاتمة

رغم كل ما قيل عن الإمام محمد عبده من مدح أو نقد، فإنه كان مبدعاً، واستطاع أن يجاوز، من خلال كتاباته وأفعاله واجتهاداته منطق الواقع، ويصح أن يطلق عليه أنه مؤسس "مدرسة الاعتدال" في وقته، وفي الفكر الإسلامي على العموم. فقد غاص في أعماق الشريعة وجوهرها، ولم يكتف بالنظرة السطحية الظاهرة، أي أنه نظر "للمضمون"، ولم يكتف "بالعنوان". وعلى الرغم من كونه قد فج منهج الاعتدال، إلا أنه كان ثورياً على واقعه المتخلف في كافة الجوانب الحضارية. وإذا كان البعض قد اهمه بالعمالة أو الخيانة حين تعامل مع الإنجليز وهادغم، أو رماه بأنه هو من أدخل المفاهيم الغربية إلى قلب العالم الإسلامي، كالعلمانية وغيرها، مما تعاني منه الأمة إلى اليوم؛ فذلك عائد إلى أفم قد حاكموه انطلاقاً من فقهرم للواقع الحالي، وليس من معرفتهم العميقة بمقتضيات العصر الذي عاشه، وبالظروف الموضوعية التي كانت من حوله. فالإمام الشافعي، مثلاً، كان قد أفتى في الحجاز بفتاوى معينة، وعندما انتقل إلى مصر أفتى بغيرها في المسائل نفسها؛ نظراً لتغير البيئة، وإن كان الزمان نفسه، فكيف بالتغير الكبير، بل الجذري، في الزمان والمكان والبيئة والظروف المحيطة ما بين الوقت الذي عاشه محمد عبده وما عاشه غيره من المفكرين المعاصرين. وعلى كلِ فإن ناقديه قلة، إذا ما تمّ قياسهم بمن أجلّه وأثنى عليه بما يستحقه، ولربما لو عاش محمد عبده اليوم بين ظهرانينا، لتبدل الكثير من آرائه في أمور السياسة ومسائل الحكم. ويكفي الإمام محمد عبده أنه قد بعث هضة فكرية وأدبية في الأمة، وبث فيها "منهج الاعتدال" الذي تبنَّه عدد من الحركات الإسلامية المعاصرة. والأمة اليوم بحاجة إلى محمد عبده جديد، يخرج بها عن المألوف الجامد والبالي، وفق ضوابط الشرع، ويدفعها للسير في الطريق الصحيح المؤدي إلى الحضارة السليمة، التي تعيد للأمة مجدها السالف، والذي لن يكون إلا ببذل الجهاهد في سبيل الله -عز وجل-، يقول تعالى(وَالَّنينَ جَاهَدُوا فينَا

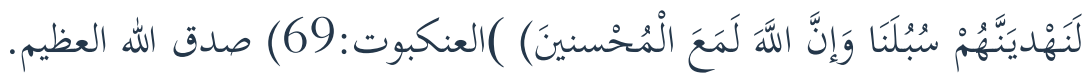

